\title{
Foraminíferos miocenos en la cuenca Neuquina, Argentina: implicancias estratigráficas y paleoambientales
}

\author{
Carolina Náñez ${ }^{1}$, Norberto Malumián ${ }^{1}$ \\ I Servicio Geológico Minero Argentino y CONICET, Benjamín Lavaisse 1194, (1107) Ciudad Autónoma de Buenos Aires, Argentina. \\ carolina.nanez@segemar.gov.ar;n.malumian@yahoo.com
}

\begin{abstract}
RESUMEN. En los perfiles Opaso y Bajada del Jagüel, situados en el bajo de Añelo, cuenca Neuquina, Argentina, las fangolitas de la Formación Jagüel, de edad maastrichtiana a daniana, están cubiertas por una sucesión de coquinas muy ricas en ostreidos, areniscas y limoarcilitas. Esta sucesión ha sido tradicionalmente asignada a la Formación Roca, unidad paleocena con su sección tipo situada unos $120 \mathrm{~km}$ hacia el sudeste. Sin embargo, una interpretación estratigráfica muy diferente, propuesta en los años setenta, consideró que las sedimentitas asignadas a la Formación Roca en estos perfiles integran en realidad la base de la suprayacente Formación Barranca de los Loros, de ambiente continental y edad miocena, y que sus muy abundantes restos de invertebrados marinos paleocenos eran retrabajados. En el presente estudio, se revisan los foraminíferos de la familia Elphidiidae provenientes de una intercalación fangolítica entre las coquinas en los perfiles Opaso y Bajada del Jagüel. Se reasignan a Porosononion granosum (d'Orbigny) ejemplares previamente identificados como Protelphidium sp. cf. P. hofkeri Haynes. Porosononion granosum es una de las especies más características de la transgresión Paranense, que inundó con un mar somero gran parte de la Argentina en el Mioceno medio-tardío, y ha sido identificada tradicionalmente como Protelphidium tuberculatum (d'Orbigny) en el Cono Sur. La presencia de esta especie sugiere que la sucesión de coquinas, areniscas y fangolitas que sobreyacen a la Formación Jagüel en los perfiles Opaso y Bajada del Jagüel no corresponden a la Formación Roca, sino que están relacionadas con la transgresión Paranense, relación que sustenta la segunda interpretación estratigráfica. En el horizonte fangolítico, Porosononion granosum conforma una asociación monoespecífica, y su paleoambiente sería marino marginal o lacustre. Ejemplares de elfidiidos provenientes de la Formación Roca en el área de Sierras Blancas, unos $12 \mathrm{~km}$ al sudoeste del perfil Opaso, se mantienen identificados como Protelphidium sp. cf. P. hofkeri. Ambas especies, $P$. sp. cf. $P$. hofkeri y P. granosum, se describen e ilustran, como así también se discuten los aspectos paleoambientales y paleogeográficos.
\end{abstract}

Palabras clave: Elphidiidae, Cuenca Neuquina, Mioceno, Paleoceno, Foraminiferos, Argentina.

\begin{abstract}
Miocene foraminifera from the Neuquén Basin, Argentina: stratigraphic and paleoenvironmental implications. At the Bajada del Jagüel and Opaso sections (Añelo low, Neuquén basin), the Maastrichtian to Danian mudstones of the Jagüel Formation, are overlain by a succession of ostreid coquinas, sandstones, and mudstones. This succession has been usually referred to the Roca Formation, a Paleocene marine unit with its type section located about $120 \mathrm{~km}$ to the southeast. A contrasting interpretation proposed by the late seventies suggests that the beds assigned to the Roca Formation in the Añelo low were actually the base of the overlying Barranca de los Loros Formation, of terrestrial paleoenvironment and Miocene age, and that their very abundant Paleocene invertebrate remains were reworked. In the present revision, the specimens of the foraminiferal family Elphidiidae recovered from a muddy horizon intercalated between the coquinas at the Opaso and Bajada del Jagüel sections, previously assigned to Protelphidium sp. cf. P. hofkeri Haynes, are identified as Porosononion granosum (d'Orbigny). Porosononion granosum is one of the most common foraminiferal species of the shallow Paranense transgression, which covered large part of Argentina during the middle-late Miocene. It has been traditionally referred to as Protelphidium tuberculatum (d'Orbigny) in Argentina. The occurrence of this species indicates that the coquinas, sandstones and mudstones overlying the Jagüel Formation at the Opaso and
\end{abstract}


Bajada del Jagüel sections should not be assigned to the Roca Formation, but are related to the Miocene Paranense transgression, thus supporting the later stratigraphic interpretation. In the muddy horizon, Porosononion granosum constitutes a monospecific assemblage, and its paleoenvironment might be either marginal marine or lacustrine. The elphidiid specimens from the Roca Formation at the Sierras Blancas area, $c a .12 \mathrm{~km}$ southwest from the Opaso section, remain identified as Protelphidium sp. cf. P. hofkeri. Both species, P. sp. cf. P. hofkeri and P. granosum, are described and illustrated, and paleoenvironmental and paleogeographic features are considered.

Keywords: Elphidiidae, Neuquén Basin, Miocene, Paleocene, Foraminifera, Argentina.

\section{Introducción}

A partir del Maastrichtiano y durante el Cenozoico, la Patagonia estuvo expuesta a varias transgresiones de origen atlántico, de carácter epicontinental y con amplio desarrollo de paleoambientes de plataforma interna y marinos marginales. Estos paleoambientes condicionaron la composición de las asociaciones de foraminíferos, con frecuentes y abundantes géneros típicos de ambientes someros como Elphidium, Cribrorotalia, Notorotalia y Protelphidium, pertenecientes a la familia Elphidiidae (Malumián y Náñez, 2011).

Las especies asignadas al género Protelphidium en la Argentina provienen de las sedimentitas depositadas por la transgresión maastrichtiana-daniana, y particularmente de las sedimentitas de la transgresión del Mioceno medio-superior, denominada Paranense o Entrerriense. En ambas transgresiones, este género ha sido comúnmente dominante en asociaciones que representan ambientes muy marginales e inestables. La proximidad morfológica entre especies de gran variabilidad y la frecuencia de ejemplares teratológicos como respuesta a ambientes extremos, sumados en ciertos casos a la deficiente preservación, han dificultado su identificación.

\subsection{Objetivo del trabajo}

El inicio de una revisión de los géneros Elphidium y Protelphidium del Maastrichtiano y Cenozoico de Patagonia y la isla Grande de Tierra del Fuego ha llevado a controlar y actualizar las asignaciones taxonómicas previas, en algunos casos estrechamente vinculadas a problemas estratigráficos de pendiente resolución. Uno de ellos, de antigua data, se refiere a la asignación formacional, temporal y paleoambiental de la sucesión de areniscas, coquinas e intercalaciones fangolíticas que suprayace a la Formación Jagüel en los perfiles Opaso y Bajada del Jagüel, en el área del Bajo de Añelo, provincia del Neuquén (Fig. 1).
Desde las primeras investigaciones geológicas en el área, esta sucesión, o parte de ella, fue asignada al Rocanense o Formación Roca, de edad daniana (e.g., Windhausen, 1914; Wichmann, 1924; Bertels, 1969, 1980; Barrio, 1990a). Sin embargo, Uliana (1979) consideró que dicha sucesión corresponde a la base de la Formación Barranca de los Loros, de paleoambiente continental y edad miocena, y que los abundantes megafósiles marinos danianos son retrabajados. En la misma sucesión, en un horizonte fangolítico intercalado entre las coquinas, Náñez y Concheyro (1997) recuperaron una asociación de foraminíferos dominada por una especie que fue determinada como "Protelphidium" sp. cf. $P$. hofkeri Haynes, 1956, acorde con la ilustrada por Bertels (1965) del perfil tipo de la Formación Roca. La baja diversidad y uniforme preservación reflejan una asociación sin retrabajo; por ello, la sucesión en cuestión de los perfiles Opaso y Bajada del Jagüel fue mantenida en la Formación Roca (Náñez y Concheyro, 1997), no obstante, se destacó la necesidad de más estudios (Ardolino y Franchi, 1997).

Una incertidumbre adicional se plantea sobre la naturaleza del ambiente acuático, entre marino o continental, adjudicable a este horizonte con Protelphidium, habida cuenta de la existencia de foraminíferos conchíferos en aguas continentales (e.g., Cann y De Deckker, 1981; Boltovskoy, 1991) y teniendo presente las discrepantes asignaciones ambientales de los depósitos paranenses en la región occidental de la Argentina (e.g., Hernández et al., 2005).

En el presente trabajo se revisa el material previamente asignado al género Protelphidium en los perfiles Opaso, Bajada del Jagüel y Puesto Sin Nombre, en la región del Bajo de Añelo, se compara con material de otras localidades del Paleoceno y Mioceno de Patagonia septentrional y de la cuenca de Rawson, y se discuten las implicancias estratigráficas y paleoambientales. 


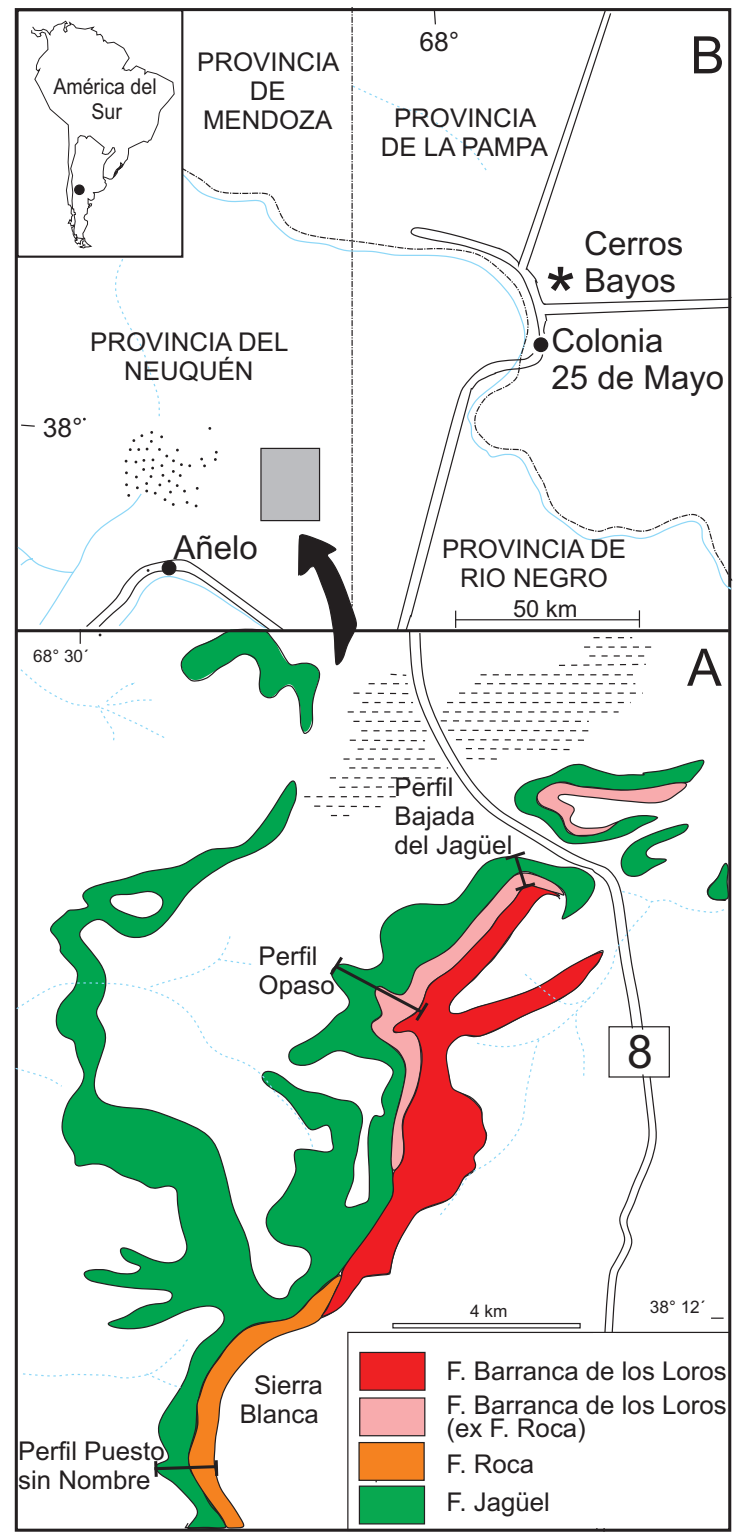

FIG. 1. A. Ubicación de los perfiles Opaso, Bajada del Jagüel y Puesto Sin Nombre y mapa geológico parcial del área de estudio en la región del Bajo de Añelo (modificado de Ardolino y Franchi, 1997); B. Mapa de ubicación relativa.

\section{Antecedentes estratigráficos y micropaleon- tológicos}

\subsection{Marco geológico y antecedentes estratigráficos}

Desde fines del Mesozoico y durante el Cenozoico, la Patagonia estuvo expuesta a cuatro principales transgresiones de origen atlántico con extendidos ambientes neríticos someros y marginales. La sedimentación marina se reconoce en varias cuencas, encontrándose la columna marina más completa en los Andes Fueguinos (Malumián, 1999; Malumián y Náñez, 2011).

La primera transgresión se inició en el Campaniano, alcanzó su máxima extensión en el Maastrichtiano y continuó durante el Daniano. Tuvo amplia cobertura 
en la Patagonia y también en la cuenca del Salado (Yrigoyen, 1999; Pérez-Panera et al., 2015). La segunda transgresión se produjo en el Eoceno medio-tardío, principalmente en la cuenca Austral, y con menor expresión en la cuenca del Colorado. La tercera, en el Oligoceno tardío-Mioceno temprano, corresponde a los denominados Juliense y Leonense, en dos pulsos bien diferenciados. La última transgresión mayor, en el Mioceno medio-tardío, corresponde al denominado Paranense o Entrerriense que cubrió con un mar somero gran parte del centro y norte del país, y en la Patagonia, principalmente su litoral.

La transgresión maastrichtiana-daniana es la única que está bien representada y documentada en la cuenca Neuquina. Sus sedimentitas integran el Grupo Malargüe, compuesto en el área oriental de la cuenca, por las formaciones Allen, Jagüel, Roca y El Carrizo. La Formación Allen se depositó en ambientes transicionales o marino marginales, tidales y estuarinos, y representa el comienzo de la transgresión del Cretácico terminal (Windhausen, 1914; Andreis et al., 1974; Uliana y Dellapé, 1981; Barrio 1990b). La suprayacente Formación Jagüel está constituida por pelitas marinas ricas en microfósiles e invertebrados de ambientes de plataforma, de edad maastrichtiana tardía a daniana (Windhausen, 1914; Wichmann, 1924; Bertels, 1969, 1980; Uliana y Dellapé, 1981; Malumián y Náñez, 1984; Barrio, 1990a; Concheyro y Náñez, 1994; Náñez y Concheyro, 1997, entre otros). La Formación Roca corresponde a facies calcáreas de ambiente marino somero, de edad daniana en la parte sur de la cuenca (Bertels, 1965) y maastrichtiana tardía hacia la parte norte (Parras et al., 1998). La Formación El Carrizo consiste en sedimentitas de ambiente continental, de edad paleocena (Uliana y Dellapé, 1981; Rodríguez et al., 2007). Parte del Grupo Malargüe se encuentra bien representado en las barrancas que rodean por el este al Bajo de Añelo, en la región nororiental de la provincia del Neuquén, donde se sitúan los perfiles Opaso, Bajada del Jagüel y Puesto Sin Nombre, que proveyeron parte del material de estudio.

La estratigrafía de la región del Bajo de Añelo, y en particular del área de Bajada del Jagüel, tiene sus primeros antecedentes a comienzos del siglo pasado, con los trabajos de Windhausen $(1912,1914)$ y Wichmann $(1922,1924)$. Una descripción y análisis de las diferentes propuestas estratigráficas y su relación con la nomenclatura estratigráfica actual la brindan Ardolino y Franchi (1997) y Rodríguez et al. (2007).
En los perfiles Opaso y Bajada del Jagüel, la sucesión comienza con unos 31 a $47 \mathrm{~m}$ de fangolitas marinas, con abundantes invertebrados fósiles y microfósiles (foraminíferos, ostrácodos, nanofósiles, palinomorfos) de edad maastrichtiana y daniana que corresponden a las denominadas Capas del Jagüel (Windhausen, 1914), y al Senoniano superior marino de Wichmann (1924). Bertels $(1969,1980)$ incluyó las fangolitas maastrichtianas en su Formación Jagüel, con localidad tipo en Bajada del Jagüel, y las danianas, en la Formación Roca, conjuntamente con las coquinas que sobreyacen a estas fangolitas. Por su parte, Uliana y Dellapé (1981) incluyeron tanto las fangolitas maastrichtianas como las danianas dentro de la Formación Jagüel, criterio litoestratigráfico similar al de Windhausen $(1912,1914)$ y Wichmann $(1922$, 1924). La Formación Jagüel comprende el contacto Cretácico-Paleógeno, aunque no se ha verificado una sucesión completa a través del límite (Náñez et al., 2002; Ballent et al., 2011 y referencias allí incluidas).

Sobre la Formación Jagüel, se apoya una sucesión de 14 a $15 \mathrm{~m}$, compuesta por calizas bioclásticas con abundante Cubitostrea, areniscas finas y fangolitas (Náñez y Concheyro, 1997), que contienen los foraminíferos estudiados en este trabajo (Fig. 2). Esta sucesión corresponde a parte del denominado Rocanense típico con fósiles marinos o Piso Rocanense en sentido estricto por Windhausen (1914), y fue también incluida en el Rocanense por Wichmann (1924). Las coquinas de la base de esta sucesión fueron agrupadas, junto con las pelitas danianas subyacentes, en la Formación Roca por Bertels (1969, 1980), unidad que tiene su localidad tipo $5 \mathrm{~km}$ al norte de la ciudad de General Roca, en la provincia de Río Negro, a unos $120 \mathrm{~km}$ al sudeste de Barranca del Jagüel.

Uliana (1979) incluyó esta sucesión de coquinas, areniscas y fangolitas con restos de invertebrados rocanenses en la base de la suprayacente Formación Barranca de los Loros, de paleoambiente continental y de edad tentativa miocena tardía-pliocena temprana. Esta formación fue propuesta originalmente como Formación Barranca de los Loros en Uliana y Camacho (1975). Uliana (1979) puntualizó que en Sierras Blancas, Jagüel de Rosauro, y Lomas Coloradas, la Formación Barranca de los Loros "se inicia con un paquete de 2 a $4 \mathrm{~m}$, constituido casi exclusivamente por restos de invertebrados de la Formación Roca". Además, menciona a la Formación Roca en el área de Sierras Blancas, al igual que Uliana y Dellapé (1981). 
OPASO

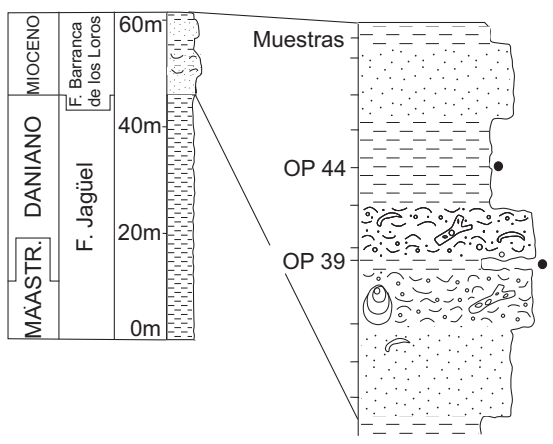

BAJADA DEL JAGÜEL

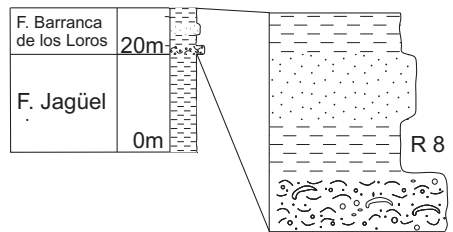

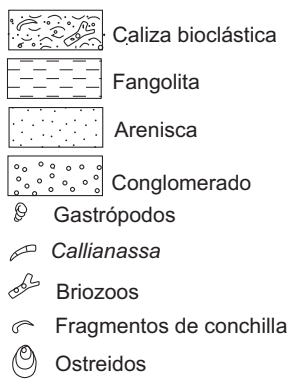

Ostreidos

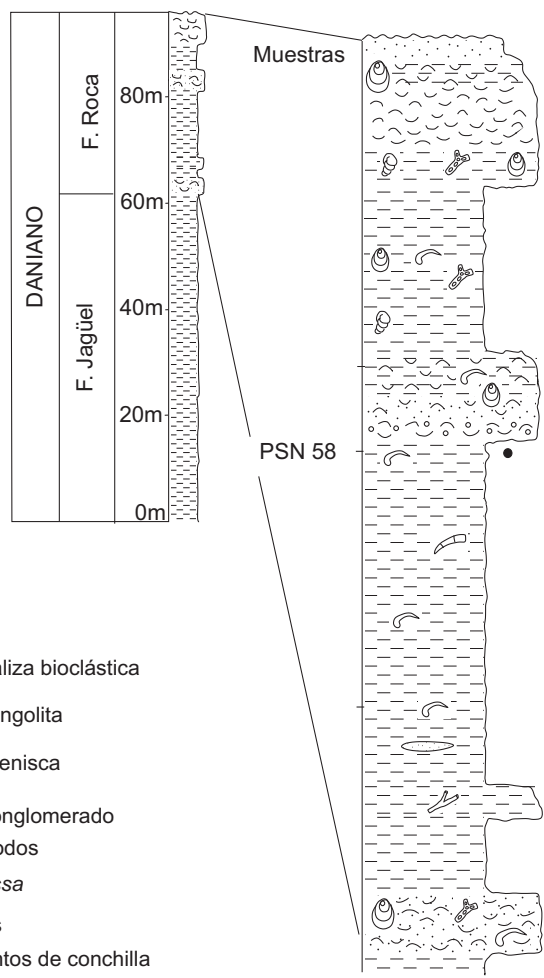

FIG. 2. Esquema estratigráfico de los perfiles Opaso y Puesto Sin Nombre (modificado de Náñez y Concheyro, 1997), y del perfil Bajada del Jagüel (modificado de Barrio, 1989, 1990a), provincia del Neuquén, Argentina.

Barrio (1990a) incluye la sucesión en cuestión en la Formación Roca, identificándola en los perfiles de Lomas Coloradas y Jagüel de los Rosauros, y le asigna un ambiente de plataforma interna a costero $y$, en particular, a los carbonatos bioclásticos, ambiente de playa o costero bajo la influencia de oleaje y tormentas, reconociendo la abrasión y el carácter resedimentado de la megafauna y la abundancia de clastos terrígenos.

Durante el levantamiento geológico del Departamento de Añelo (Ardolino et al., 1995), Náñez, C. y Concheyro, A. muestrearon las capas asignadas a la Formación Roca con fines micropaleontológicos, como complemento adicional al muestreo de la Formación Jagüel, foco de atención por contener el límite Cretácico-Paleógeno (Náñez y Concheyro, 1997). En el perfil Opaso, se encontró una lente fangolítica que alcanza 2 a $3 \mathrm{~m}$ de espesor, intercalada entre las areniscas fosilíferas y calizas bioclásticas "rocanenses" suprayacentes a la Formación Jagüel (Fig. 2). En estas fangolitas se recuperó una asociación dominada por una especie que fue identificada como "Protelphidium" sp. cf. P. hofkeri, asimilada con la previamente ilustrada para un horizonte de similar litología y posición estratigráfica en el perfil tipo de la Formación Roca (Bertels, 1965). Dada la alta dominancia de esta especie en la lente fangolítica del perfil Opaso, se interpretó que la asociación estaba in situ y que reflejaba un ambiente marino restringido, probablemente hiposalino (Náñez y Concheyro, 1997). Consecuentemente, las capas se asignaron a la Formación Roca, aunque con reservas (Ardolino y Franchi, 1997, p. 67). Sobre ellas se disponen arcilitas rojizas, de ambiente continental, incluidas en la Formación Barranca de los Loros. Los restos de vertebrados de esta Formación fueron referidos a la Edad Friasense (Pascual et al., 1984), miocena media temprana, 
entre 15,5 a 16,5 Ma (Flynn y Swisher, 1995). Teniendo en cuenta una probable correlación con la Formación Cerro Azul, discutida por Rodríguez et al. (2007), Kramarz et al. (2011) sugieren una edad miocena tardía para la Formación Barranca de los Loros. Esta probable correlación se basa en la similitud litológica, pero Rodríguez et al. (2007) destacan que los mamíferos de la Formación Cerro Azul son referidos por distintos autores a las Edades Mamífero Chasicoense y Huayqueriense, del Mioceno Tardío (e.g., Montalvo y Casadío, 1988; Verzi et al., 2008; Folguera y Zárate, 2009), y ubican la Formación Barranca de los Loros en el Mioceno medio.

Dentro del ámbito de la cuenca Neuquina, no se han mencionado sedimentitas marinas más jóvenes que paleocenas, a excepción de los niveles con invertebrados marinos de la parte inferior de la Formación Vaca Mahuida. A estos niveles fosilíferos, sumergidos por el embalse de Casa de Piedra, se les ha asignado una probable edad máxima oligocena tardía a miocena temprana (Rodríguez et al., 2007). Los términos superiores de la Formación Vaca Mahuida contienen vertebrados friasenses, por lo que su edad se extendería hasta el Mioceno medio. En el área de la Hoja Neuquén, que incluye la región de estudio, la Formación Vaca Mahuida es cubierta en discordancia por la Formación Barranca de los Loros, o por delgadas cubiertas de rodados sobre superficies de pedimentación (Rodríguez et al., 2007).

\subsection{El género Protelphidium y morfotipos similares en la Argentina}

Los registros estratigráficamente más antiguos de asignaciones al género Protelphidium en la Argentina se inician con la Formación Allen, en la provincia del Neuquén. Esta formación, en la localidad de Auca Mahuevo (6900' W; 37³0' S), brindó una asociación de foraminíferos de baja diversidad recuperada de sus $10 \mathrm{~m}$ basales. La asociación, dominada por Protelphidium sp., con más del $70 \%$ de las conchillas con anormalidades, está compuesta por formas aglutinadas, porcelanáceas y hialinas (probables gavelinélidos). La microfauna, que incluye abundantes ostrácodos no marinos, reflejaría ambientes subtidales a intertidales próximos a la línea de costa, con ambientes parcialmente protegidos como albúferas en estuarios. El alto porcentaje de ejemplares anormales se atribuyó a las fluctuaciones en la salinidad, propias del ambiente marino marginal, sumado a eutroficación. La edad asignada a la asociación es campaniana tardíamaastrichtiana temprana por posición estratigráfica (Carignano y Garrido, 2006; Ballent y Carignano, 2008; Carignano y Ballent, 2009).

Para el Maastrichtiano, se describió Protelphidium primitivum Náñez y Malumián, 2008, proveniente de la Formación Jagüel, en Liu Malal, y de la Formación Roca en Malargüe, provincia de Mendoza, así como del Miembro Aguada Cecilio, Formación Arroyo Barbudo, en Aguada Cecilio, provincia de Río Negro, todas localidades de la cuenca Neuquina-Colorado. Esta especie se encuentra en asociaciones de baja diversidad, habitantes de paleoambientes someros y marginales (Náñez y Malumián, 2008).

En el primer estudio micropaleontológico sobre la Formación Roca, asignada al Daniano, Bertels (1965) ilustra a Protelphidium sublaeve (Ten Dam, 1944) y Protelphidium cf. hofkeri Haynes, 1956, representados por abundantes ejemplares dominantes en las asociaciones de baja diversidad de los términos superiores netamente regresivos del perfil tipo de la formación. Los ejemplares de ambas especies son incluidos en Protelphidium hofkeri por Malumián y Caramés (1995). En la sección Cerro Azul, provincia de Río Negro, en la parte superior de la Formación Roca, de ambiente marino marginal, esta especie conforma asociaciones monoespecíficas con un alto porcentaje de conchillas anómalas, atribuidas a condiciones de estrés ambiental (Ballent y Carignano, 2008). Protelphidium hofkeri es reconocida también en la Formación Salamanca, Daniano de la cuenca del Golfo de San Jorge, pero escasamente representada (Méndez, 1966; Masiuk, 1967; Bertels, 1975; Malumián y Caramés, 1995).

Para el Oligoceno tardío, en la Formación San Julián, cuenca Austral, se reconoció una forma bajo la denominación de Elphidium sp. 2724 (Náñez, 1989), asignable a Haynesina depressula (Walker y Jacob, 1798, en Kanmacher, 1798), que en Nueva Zelanda se conoce a partir del Oligoceno (Hayward et al., 1997). Es la única especie de morfología próxima a Protelphidium en el Oligoceno superior- Mioceno inferior de Patagonia y Tierra del Fuego.

Es destacable que durante el Mioceno temprano, en sedimentitas de la Formación Monte León y unidades correlacionables en varias cuencas patagónicas, hasta la fecha no se reconocen morfotipos similares o referibles a Protelphidium, pese a que dentro de 
la gran amplitud latitudinal cubierta por el mar muy probablemente debieron existir condiciones ecológicas propicias para su existencia.

Para el Mioceno medio-tardío, la especie más frecuente y emblemática de la transgresión Paranense ha sido tradicionalmente asignada a Protelphidium tuberculatum (d'Orbigny, 1846), o bien comparada con esta especie. Inicialmente reconocida en la Formación Paraná por Pisetta (1968), se ilustró para el subsuelo de la cuenca del Salado, provincia de Buenos Aires, denominando una biozona informal (Malumián, 1970). En el centro y norte de la Argentina compone asociaciones de muy baja diversidad (e.g., Zabert y Barbano, 1982-1984; Marengo, 2000, 2006). En Patagonia septentrional, se conoce en la Formación Barranca Final (Malumián et al., 1998), en una intercalación marina en la Formación Río Negro (Malumián y Náñez, 1984), en afloramientos de la Formación Puerto Madryn cercanos a Sierra Grande (Busteros et al., 1998), y en el sureste de la provincia de La Pampa (Parras et al., 2000). En la perforación Puelche, de la cuenca Colorado Marina, por su abundancia ha dado nombre a una biozona (Becker y Bertels, 1980). El registro más austral de esta especie se reconoce en Península Valdés (Masiuk et al., 1976; Caramés et al., 2004). Llamativamente, la frecuencia y abundancia de esta especie en el Paranense contrasta fuertemente con su ausencia, incluso de morfotipos similares, dentro de las sedimentitas del Patagoniense, y marca una discontinuidad en el registro cronológico entre formas paleógenas y neógenas atribuidas al género Protelphidium. Protelphidium tuberculatum tampoco ha sido citada en las asociaciones modernas de la plataforma continental argentina, donde la especie morfológicamente más cercana es Elphidium gunteri Cole, 1931.

\section{Material y métodos}

El material objeto de revisión proviene principalmente del perfil Opaso, bajo de Añelo, provincia del Neuquén, de niveles previamente asignados a la Formación Roca y, en particular, de la muestra OP39 (Fig. 2), tomada de una lente fangolítica intercalada entre calizas bioclásticas (Náñez y Concheyro, 1997). Para el presente estudio, se recuperaron más ejemplares de la misma muestra y se analizaron mediante microscopio electrónico, especialmente sus detalles aperturales. Se ha contado, además, con material del perfil de Bajada del Jagüel, levantado por Barrio (1989, 1990a), quien en su momento proporcionó las muestras a fin de anticipar información micropaleontológica al levantamiento geológico del Departamento de Añelo.

Los ejemplares de los perfiles Opaso y Bajada del Jagüel se compararon con los previamente asignados al género Protelphidium provenientes de otras localidades; en particular, de muestras de inyección entre 450-60 y 600-610 m bajo boca de pozo, del pozo Tayra $\mathrm{x}-1\left(42^{\circ} \mathrm{S}\right.$ y $61^{\circ} \mathrm{W}$, cuenca de Rawson), asignadas al Mioceno medio-Plioceno (Marinelli y Franzin, 1996). También se contó con ejemplares provenientes de la Formación Barranca Final en su localidad tipo (Malumián et al., 1998).

Asimismo, se compararon los ejemplares previamente asignados a Protelphidium hofkeri o Protelphidium cf. hofkeri de niveles de la Formación Roca, en el perfil Puesto Sin Nombre (área de Sierras Blancas, provincia del Neuquén), muestra PSN 58 (Náñez y Concheyro, 1997). También se contó con material del perfil Cerros Bayos, de la provincia de La Pampa, muestra M-13 (Casadío y Concheyro, 1992; Náñez, 1998), y con dos ejemplares de la Formación Salamanca, de afloramientos de la provincia del Chubut, depositados en la colección micropaleontológica del SEGEMAR, uno de ellos ilustrado por Malumián y Caramés (1995). Además, se consultaron ejemplares del perfil tipo de la Formación Roca, depositados por Bertels en la colección micropaleontológica de la Facultad de Ciencias Exactas y Naturales, Universidad de Buenos Aires.

Los ejemplares ilustrados están depositados en la colección micropaleontológica del SEGEMAR, bajo los números de catálogo 1759 y 2992 a 3022.

\section{Resultados y discusión}

\subsection{Revisión taxonómica: Implicancias estratigráficas}

En la presente revisión taxonómica del género Protelphidium de la región del Bajo de Añelo, se reconocen dos especies: una paleógena, Protelphidium sp. cf. P. hofkeri, y otra neógena, Porosononion granosum (d'Orbigny, 1846). La primera se evidencia en niveles de la Formación Roca, en el perfil Puesto Sin Nombre, área de Sierras Blancas, provincia de Neuquén. 
La segunda, $P$. granosum, conforma la asociación recuperada de la muestra OP39 en el perfil Opaso y de un horizonte correlacionable en el perfil Bajada del Jagüel. Esta especie había sido previamente identificada por Náñez y Concheyro (1997) como "Protelphidium" sp. cf. P. hofkeri, dada: a) la general similitud morfológica externa con la especie comparada, b) la equivalente posición estratigráfica con el horizonte con $P$. cf. hofkeri en el perfil tipo de la Formación Roca (Bertels, 1965), y c) las características de aberturas o forámenes múltiples, ilustrados para conchillas provenientes de esta última localidad (Bertels, 1965), similares a las de los ejemplares de los perfiles Opaso y Bajada del Jagüel. Una de las características morfológicas distintivas de $P$. granosum son sus tubérculos umbilicales grandes y romos, pero por deficiente preservación y fuerte disolución, gran parte de los ejemplares de los perfiles Opaso y Bajada del Jagüel perdieron los tubérculos que forman el relleno umbilical. Tanto en el perfil Opaso como en el perfil Bajada de Jagüel, la especie domina la asociación de foraminíferos, que está contenida en un horizonte fangolítico. La preservación es pobre, con una fuerte corrosión de la pared de las conchillas. Acompañan algunas conchillas de foraminíferos danianos, que se consideran retrabajadas. En el perfil Opaso, se encuentran escasos y fragmentados oogonios, probablemente autóctonos, y abundantes ostrácodos.

La reasignación de los ejemplares de los perfiles Opaso y Bajada del Jagüel a Porosononion granosum sugiere una edad neógena para la sucesión suprayacente a la Formación Jagüel, anteriormente asignada a la paleógena Formación Roca (Fig. 3).

Porosononion granosum, identificado tradicionalmente como Protelphidium tuberculatum, $P$. cf. tuberculatum, o Elphidium cf. tuberculatum en los estudios micropaleontológicos del Cono Sur, es la especie más característica de la transgresión Paranense y su acotación cronológica depende de la edad de la transgresión y de la posición estratigráfica de sus sedimentitas.

Porosononion granosum se reconoce con identificación tentativa también en el Mioceno de la

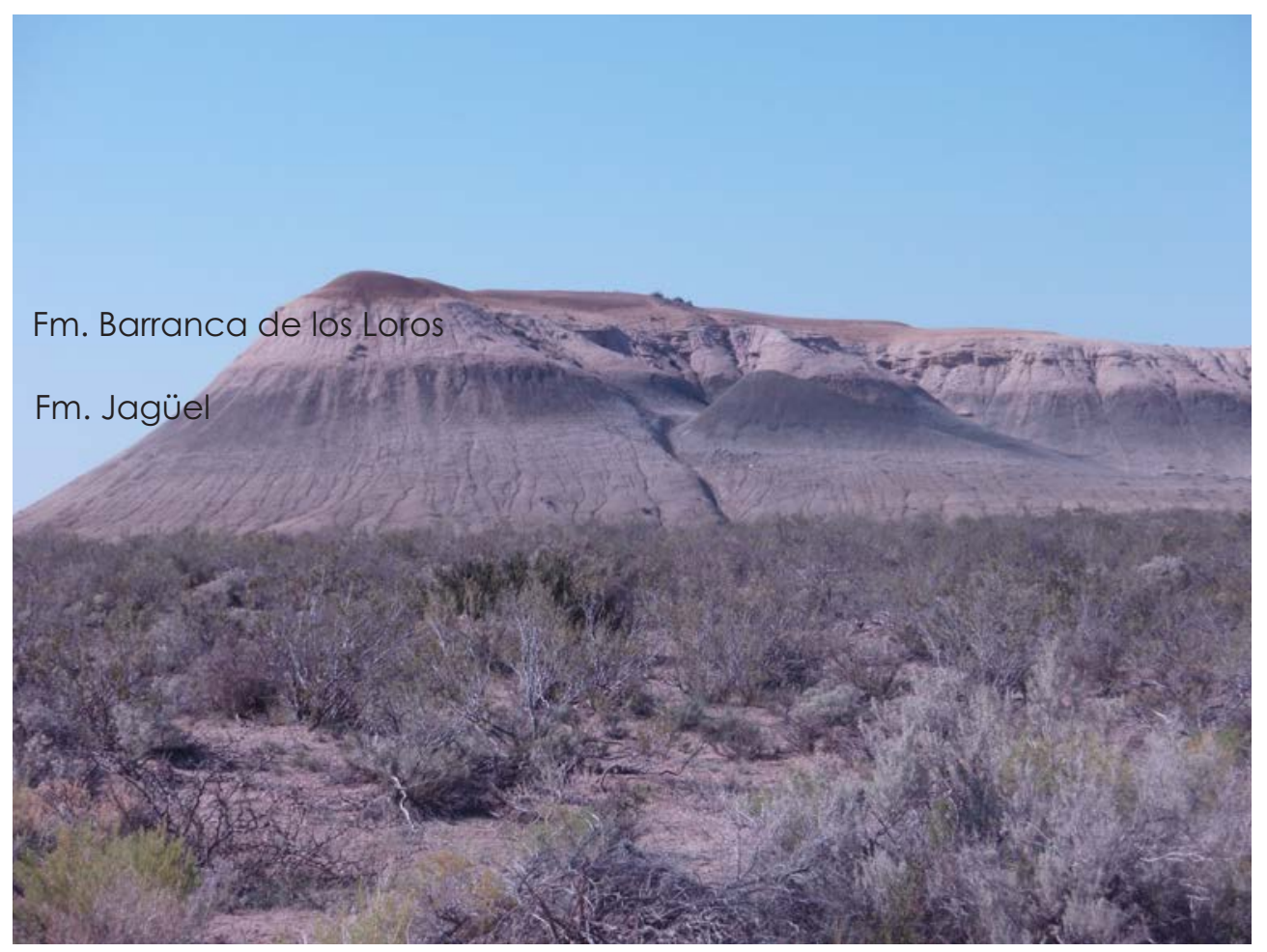

FIG. 3. Vista panorámica de la localidad de Bajada del Jagüel, con las coquinas y areniscas fosilíferas de la Formación Barranca de los Loros, suprayacentes a la Formación Jagüel. 
Amazonia colombiana y peruana, de ambiente estuarino (Boonstra et al., 2015), y con otras denominaciones en el Mioceno de la cuenca de Pelotas, Brasil (ver ítem de Paleontología Sistemática). Fuera del continente, está extendida en el Neógeno, Cuaternario y Reciente europeo (e.g., Brodniewicz, 1972; Jorissen, 1987; Poignant et al., 2000; Harzhauser y Piller, 2004).

El horizonte con P. granosum en los perfiles de Opaso y Bajada del Jagüel está comprendido entre las pelitas danianas de la Formación Jagüel, y la parte superior, continental, de la Formación Barranca de los Loros, de edad miocena media según Rodríguez et al. (2007). Una edad equiparable a la de la transgresión Patagoniense del Oligoceno tardío-Mioceno temprano para el horizonte con $P$. granosum podría ser posible, pero no se conocen registros de Protelphidium o morfotipos similares dentro del Patagoniense, particularmente en la Formación Monte León y equivalentes. Tampoco se reconoce esta especie en la denominada transgresión de Laguna Paiva, de edad mayormente aquitaniana (25-21 Ma), extendida en las cuencas Chacoparanense y del Salado (Marengo, 2006). Consecuentemente, el nivel con $P$. granosum en los perfiles Opaso y Bajada del Jagüel, se asigna al Paranense. Esta asignación se condice con Uliana (1979), quien incluyó en la Formación Barranca de los Loros a las calizas bioclásticas con fósiles rocanenses, que engloban el nivel fangolítico con P. granosum (Fig. 3). Asimismo, es coherente con la interdigitación entre el "Paranense" y la alloformación II, que incluye la Formación Barranca de los Loros, indicada por Folguera et al. (2015, Fig. 4).

En general, la transgresión Paranense ha sido datada según los microfósiles en el lapso Mioceno mediotardío. Los primeros estudios micropaleontológicos mediante ostrácodos dataron a la Formación Entre Ríos, aflorante en Victoria, en el Mioceno (Rossi de García, 1966). Al tratarse de una transgresión muy somera y de ambiente hiposalino, las asociaciones de foraminíferos son de muy baja diversidad y carecen o son muy escasos los elementos planctónicos cronológicamente diagnósticos.

Para el Paranense del subsuelo de la cuenca del Salado, Malumián (1970) señala que la conjunción de foraminíferos y ostrácodos sugiere una edad miocena tardía, siendo uno de los criterios la abundancia de Nonionina granosa, considerada como sinónima de Protelphidium tuberculatum, en el Mioceno Superior de la cuenca de Viena. La biozona de Porosononion granosum en las cuencas de Viena y Styria corresponde al Sarmatiano superior, piso actualmente asignado a la parte cuspidal del Mioceno medio (Harzhauser y Piller, 2004). Los nanofósiles recuperados de la sección media del Paranense en el subsuelo de la cuenca del Salado, indican una edad correspondiente a la zona NN6 (Martini, 1971; Young, 1998), Serravaliano, Mioceno medio (Marengo y Concheyro, 2001; Marengo et al., 2005; Marengo, 2006, 2015). Costa afuera en la cuenca del Salado, el Paranense se identifica con un intervalo rico en nanofósiles diagnósticos, correspondientes a las zonas NN5 y NN6 (Malumián y Náñez, 1996).

Para el subsuelo de la cuenca del Colorado, Malumián (1970) sugirió, para sedimentitas que atribuyó al Paranense, una edad no menor que miocena media por los foraminíferos planctónicos Cassigerinella chipolensis (Cushman y Ponton, 1932) y Globoturborotalita woodi woodi (Jenkins, 1960), algo más antigua que el Paranense de la cuenca del Salado. Estas sedimentitas de la cuenca del Colorado fueron asignadas al Paranense por la afinidad señalada por los ostrácodos, pero no contienen Porosononion granosum. En este trabajo, se considera que corresponden a capas marinas de mayor antigüedad, que se incluyen en el Patagoniense. Horizontes asignables al Paranense por el contenido de Porosononion granosum se han identificado en la perforación DNGM Gil-1, del flanco norte de la cuenca del Colorado. En la misma cuenca, en la localidad tipo de la Formación Barranca Final, los dinoflagelados sugieren una edad miocena media¿tardía? (Guler et al., 2002) para los niveles que contienen la asociación o biozona de Protelphidium tuberculatum. Edades isotópicas ${ }^{87} \mathrm{Sr} /{ }^{86} \mathrm{Sr}$ entre 9,61 y 6,48 Ma, Tortoniano, fueron informadas para el perfil tipo de la Formación Barranca Final (Palazzesi et al., 2014). En la cuenca Colorado Marina, sobre la plataforma continental, el tramo con predominancia de Protelphidium tuberculatum fue asignado al Mioceno superior-Plioceno inferior por el rango bioestratigráfico de esa especie en la cuenca de Viena e Italia (Becker y Bertels, 1980).

Porosononion granosum ha sido ilustrada bajo el nombre de Protelphidium tuberculatum por Malumián y Náñez (1984) para la intercalación marina en la Formación Río Negro, denominada Facies Balneario La Lobería (Angulo y Casamiquela, 1982), correlacionada con la Formación Puerto Madryn, sobre la base de sus moluscos (del Río 1990, 2000; del Río et al., 2013). Zavala y Freije (2000) también la asignan al 


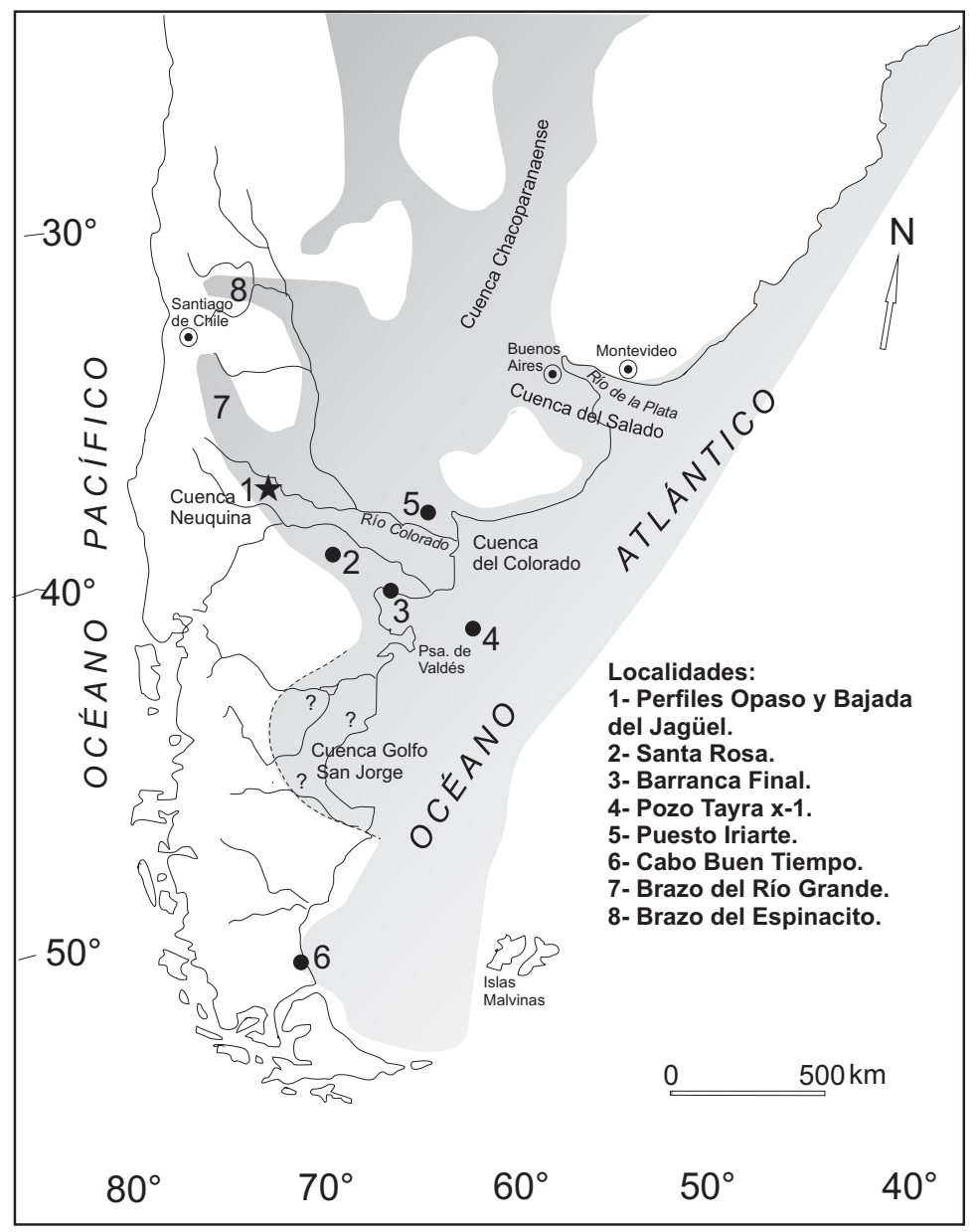

FIG. 4. Esquema paleogeográfico de la transgresión Paranense (modificado de Ramos y Alonso, 1995; Pérez et al., 1996; del Río et al., 2013). En las cuencas Neuquina y del Colorado, el mar habría penetrado al menos hasta la localidad de Santa Rosa (Provincia de Río Negro), donde se ha encontrado Ostrea alvarezii d'Orbigny, $y$ entre foraminíferos muy deficientemente preservados destaca Elphidium discoidale (d'Orbigny), indicador de la actual subprovincia biogeográfica Nordpatagónica, y característico de ambientes marinos marginales. Más hacia el oeste, no se documentaron evidencias inequívocas de ambiente marino. En los perfiles Opaso y Bajada del Jagüel, los foraminíferos, asociados a escasos y fragmentados oogonios de carofitas, pueden corresponder tanto a un ambiente marino marginal como lacustre. El origen lacustre propuesto para los depósitos del antepaís andino, incluido el denominado brazo del Espinacito, y la región de Sierras Pampeanas, restringiría el mar Paranense a la región oriental de la Argentina (Aceñolaza, 2000, 2007; Ruskin et al., 2011).

Tortoniano, por correlación con los afloramientos de Península Valdés datados por Zinsmeister et al. (1981) y por la posición infrastante a fauna de edad Mamífero Montehermosense (Aramayo, 1987), actualmente considerada miocena tardía a pliocena temprana (Flynn y Swisher, 1995; Cione y Tonni, 2005). Etcheverría et al. (2006) estiman que la Formación Río Negro es de edad pliocena temprana, y Folguera et al. (2015) la sitúan en el Mioceno tardío-Plioceno temprano.
Para la Formación Puerto Madryn, en península Valdés, Malumián y Masiuk (1973), Masiuk et al. (1976) y Caramés et al. (2004) asignaron una edad miocena media-tardía para los niveles con abundantes ejemplares de Protelphidium tuberculatum. Scasso et al. (2001), mediante análisis de ${ }^{87} \mathrm{Sr} /{ }^{86} \mathrm{Sr}$ sobre pectínidos y ostreas, determinaron una edad de 10,0 $\pm 0,3 \mathrm{Ma}$, Tortoniano (Mioceno tardío), coherente con la de ca. 9,4 Ma obtenida por Zinsmeister et al. (1981) por datación de K-Ar en el área de Bahía 
Cracker. Estas edades corresponden a la parte baja del Mioceno superior, y a las biozonas NN9 y NN10 de nanoplancton calcáreo (Lourens et al., 2004), con el límite del Mioceno medio/superior, o sea la base del Tortoniano, datado en 11,63 Ma (Lourens et al., 2004; Hilgen et al., 2012).

Pérez (2013) obtuvo una edad isotópica ${ }^{87} \mathrm{Sr} /{ }^{86} \mathrm{Sr}$ de 9,47 Ma, Tortoniano, para la Formación Paraná, en Punta Gorda Sur, provincia de Entre Ríos, congruente con estudios previos (e.g., Herbst y Zabert, 1979, 1987; Cione et al., 2000; Martínez y del Río, 2005). Las relaciones faunísticas de la Formación Paraná la vinculan con la Formación Camacho del Uruguay (e.g., Herbst y Zabert, 1979 y referencias en Pérez, 2013). Dataciones de ${ }^{87} \mathrm{Sr} /{ }^{86} \mathrm{Sr}$ sobre ostreas y foraminíferos de esta última formación indican una edad burdigaliana, Mioceno temprano, con edades de 17-18 Ma (Sprechmann et al., 2008, 2010). Los foraminíferos datados provienen del pozo El Chuy $\mathrm{N}^{0} 364$, de niveles en que están asociados con Elphidium cf. tuberculatum (Sprechmann, 1978), pero esta asociación puede deberse a la caída de material pozo abajo.

Hernández et al. (2005) reconocen dos pulsos transgresivos dentro del Mioceno medio y tardío para la región cercana a los Andes en la Argentina y sur de Bolivia, uno entre 15 y $13 \mathrm{Ma}$, que cubre el área de estudio del presente trabajo, y el otro, arealmente más restringido, entre $10 \mathrm{y} \sim 5$ ? Ma.

Marengo (2015) acepta una edad amplia entre $15 \mathrm{y}$ 9,5 Ma para la transgresión del Entrerriense-Paranense y destaca que algunos ejemplares de foraminíferos planctónicos sugieren una edad miocena media, y que la sección media de esta transgresión en la cuenca del Salado indica una edad equivalente a la Zona NN6 de nanoplancton calcáreo, Mioceno medio.

Las capas portadoras de Porosononion granosum $y$, en particular, el horizonte monoespecífico del perfil Opaso (muestra OP39) son considerados como muy probablemente vinculados a la transgresión Paranense, dada la distribución de esta especie en la Argentina, y asignadas, a falta de indicadores temporales más precisos, al Mioceno medio-tardío.

\subsection{Retrabajo versus in situ}

El carácter monoespecífico de la asociación que Porosononion granosum conforma en los perfiles Opaso y Bajada del Jagüel sugiere su condición autóctona, sustentada también por la litología fangolítica del horizonte portador, indicativa de baja energía depositacional. La edad neógena de $P$. granosum evidencia el retrabajo de los abundantes megafósiles paleocenos.

El retrabajo de megainvertebrados rocanenses fue reconocido en otras localidades y formaciones de la cuenca Neuquina. Wichmann (1924) menciona fósiles del Piso Rocanense silicificados, corroídos y redepositados en margas y arcillas rojizas del Pliocénico que se asignan actualmente a la Formación Barranca de los Loros en las localidades de Bajada del Palo y Lomas Coloradas (Ardolino y Franchi, 1997). Ramos (1981) menciona invertebrados de la Formación Roca en la Formación Carrere, asignada al Oligoceno, y considera que explicarían la interpretación de Groeber $(1956,1959)$, quien separó un Roca I, de otro Roca II, discordante y más pobre en megafauna. Precisamente, Groeber (1959) habría asignado las coquinas del perfil Bajada del Jagüel a su Roca II, de carácter transgresivo y discordante, según el mapa de afloramientos (Groeber, 1959, p. 130; Bertels, 1980, p. 50). Rodríguez et al. (2007) mencionan megafauna rocanense retrabajada dentro de las formaciones Vaca Mahuida y Barranca de los Loros, en el ámbito de la Hoja geológica Neuquén.

La altísima concentración de fósiles rocanenses en la base de la Formación Barranca de los Loros en el perfil Opaso genera la sospecha de que otros afloramientos asignados al Paleoceno en la Patagonia septentrional, incluso en la cuenca del Golfo de San Jorge, pueden corresponder también a depósitos miocenos, que alcanzarían en ese caso extensión regional, tal como propuso Groeber (1959) para el Roca II.

Uliana (1979) asignó a la Formación Roca las calizas fosilíferas que suprayacen a la Formación Jagüel en Sierras Blancas, a diferencia de los niveles coquinoides de los perfiles Opaso y Bajada del Jagüel que incluyó en la Formación Barranca de los Loros. La asociación de foraminíferos de la Formación Roca en el perfil Puesto Sin Nombre, en el área de Sierras Blancas, se caracteriza no solo por la presencia de Protelphidium sp. cf. P. hofkeri, sino también por la abundancia de Boltovskoyella paleocenica Náñez, 1988. Esta última especie fue identificada por Bertels (1965) como Rosalina cf. ystadiensis Brotzen, 1948, en el perfil tipo de la Formación Roca, junto con microfauna relativamente diversificada, $y$ también en los términos superiores regresivos de esa Formación, asociada a Protelphidium (Bertels, 1965; 
Náñez, 1998). En las coquinas y areniscas de la base de la Formación Barranca de los Loros en los perfiles Opaso y Bajada del Jagüel, Boltovskoyella paleocenica es escasa y esporádica, y al igual que los megafósiles rocanenses, se considera retrabajada.

Se interpreta que las coquinas de la base de la Formación Barranca de los Loros correspondería al Roca II, discordante y transgresivo, de Groeber (1959), mientras las coquinas y bancos ostreros del perfil Puesto Sin Nombre representan al Roca I, el verdadero, equiparable al de la localidad tipo de la Formación Roca, al norte de la ciudad de General Roca. Groeber (1959) consideró al Roca I de edad senoniana y al Roca II de edad daniana, pero advierte que falta la justificación paleontológica que los diferencie. El hallazgo de microfósiles miocenos en capas asignables al Roca II puede representar esa justificación.

La edad de la Formación Roca, la verdadera o Roca I en el sentido de Groeber (1959), tradicionalmente aceptada como daniana, está actualmente bajo revisión, debido a numerosos indicadores que sugieren una edad más joven, siempre dentro del Paleógeno temprano.

\subsection{Paleogeografía y paleoambiente}

La transgresión Paranense cubrió extensas áreas de la Argentina, con un mar muy somero (Fig. 4). A diferencia de las anteriores transgresiones cenozoicas, ocupó amplias regiones del centro y norte del país. Los bosquejos paleogeográficos de distintos autores en líneas generales coinciden en la extensión del mar Paranense en el oriente de la Argentina, pero hay discrepancias en cuanto al origen acuático marino o continental de las sedimentitas asignadas al Paranense en la región occidental. Windhausen (1931) mencionó para esa región subandina un mar de aguas salobres y muy transitorias. Ramos y Alonso (1995) bosquejan el límite occidental de la transgresión Paranense en el noroeste del país, considerando muy probable la existencia de depósitos marinos miocenos en la región del río Grande de la Provincia de Jujuy.

Pérez et al. (1996) postulan dos brazos del mar paranense en las provincias de San Juan y Mendoza. El primero, denominado Brazo del Espinacito, está basado en el hallazgo de microforaminíferos en preparados palinológicos, pero su carácter marino es desestimado por Ruskin et al. (2011). El segundo, denominado Brazo del Río Grande, en el sur de la provincia de Mendoza, tiene como antecedentes menciones de Groeber (1949), Criado Roque (1950), Herrero Ducloux e Yrigoyen (1952). Pérez et al. (1996) tienen en cuenta para la postulación de este brazo marino la mención de nanofósiles y foraminíferos en esa región por Yrigoyen (1993), basada a su vez en una comunicación personal de Legarreta. Este brazo es incluido en el bosquejo paleogeográfico del mar Entrerriense por del Río y Martínez (1998), dejando abierta su vinculación con los depósitos del oriente rionegrino. Bossi y Gavriloff (1998) sintetizan las distintas concepciones paleogeográficas y asignan condiciones parálicas a los depósitos correlacionados con el Paranense en la provincia de Tucumán, mientras Aceñolaza $(2000,2007)$ refiere los depósitos occidentales a ambientes lacustres, excepto un angosto brazo de mar que alcanza el valle de Santa María en Catamarca. Bertolino et al. (2000) sugieren un ambiente marino para sedimentitas relacionadas con el Paranense en las Sierras Pampeanas de Córdoba, basándose en facies sedimentarias y trazas fósiles, también desestimado por Ruskin et al. (2011).

Los foraminíferos en algunos de estos afloramientos de la región noroccidental del país han servido de base para sugerir un ambiente conectado con el mar (e.g., Bertels y Zabert, 1980; Bertels, 1979), dado que los foraminíferos fósiles son generalmente indicadores de paleoambientes marinos. Sin embargo, se han descrito algunos casos de foraminíferos fósiles en depósitos originados en cuerpos de agua continentales, sin conexión con el mar, especialmente para el Cuaternario (e.g., Cann y De Deckker, 1981; Patterson, 1987; Boudreau et al., 2001; Abu-Zied et al., 2007) y para algunos depósitos cenozoicos más antiguos (e.g., Anadón, 1989). En la Argentina, se han mencionado algunos casos similares, como en los depósitos lacustres pleistocenos en las Salinas del Bebedero, provincia de San Luis, y Laguna La Amarga, provincia de Buenos Aires (González et al., 1981). Estos autores proponen como la hipótesis más factible para explicar la presencia de foraminíferos en estos cuerpos lagunares continentales, una introducción foránea o accidental a través de agentes de dispersión naturales, con un poblamiento "en rosario" aprovechando la amplia distribución de áreas palustres. La distribución de los foraminíferos de afinidad Paranense en sedimentitas del antepaís andino, que por otros restos fósiles y sus facies sedimentarias son asignados a ambientes lacustres, es explicada por Gavriloff (2013) como debida al transporte por medio de aves. 
Hernández et al. (2005) diferencian dos pulsos transgresivos dentro del Paranense, especialmente en el interior del continente, mientras hacia el margen continental la sedimentación marina habría sido más continua. Para el pulso más antiguo, entre 15 y $13 \mathrm{Ma}$, señalan un origen tectónico y eustático, que habría utilizado viejas zonas de acomodación de sedimentos, desarrollándose a lo largo de los valles de los ríos Colorado y de La Plata, con el límite occidental muy irregular, y poco definido. Estiman para este pulso una influencia marina, posiblemente estuarina, interpretación que consideran tentativa por basarse en la presencia de Corbicula sp. y de foraminíferos que también podrían ser de cuerpos de agua continentales. Se inclinan por una interpretación marina debida a la amplia extensión de sus depósitos y la coincidencia con un alto eustático. Por el contrario, Ruskin et al. (2011), basados en el análisis de isótopos estables, favorecen un ambiente lacustre para los afloramientos del antepaís andino, en las Sierras Pampeanas y en la Cordillera Frontal.

Las sedimentitas de la transgresión Paranense se reconocen desde la cuenca Chacoparanense hasta la península Valdés, en afloramientos y en el subsuelo (ver ítem 4.1). En la cuenca del golfo de San Jorge, se mencionaron fáunulas entrerrienses (Frenguelli, 1929; Tapia, 1929), esta última asignada al Rionegrense por Feruglio (1949), pero la presencia de la transgresión paranense en esta cuenca no tiene aceptación general (e.g., Bellosi, 1995). Los afloramientos de la Formación Chenque mediante nanoplancton calcáreo han sido asignados a edades tan jóvenes como Serravalliano (Simeoni, 2009) pero en conflicto con edades isotópicas más antiguas asignables al Patagoniano (Cuitiño et al., 2015) y que no han brindado hasta el momento Porosononion granosum. Consecuentemente, el límite austral de la distribución de esta especie sería la península Valdés.

Afloramientos en el cabo Buen Tiempo, provincia de Santa Cruz, cuenca Austral, han sido datados mediante análisis de ${ }^{87} \mathrm{Sr} /{ }^{86} \mathrm{Sr}$ sobre pectínidos en $8,95 \pm 0,82 \mathrm{Ma}$, y correlacionados con el Paranense en la parte más alta de la Formación Puerto Madryn, en la península Valdés (del Río et al., 2013). Esta localidad, reconocida en la literatura geológica desde fines del siglo XIX (ver antecedentes en del Río et al., 2013), fue incluida en el mapa paleogeográfico del Paranense por Windhausen (1931).

Las sedimentitas paranenses más cercanas a las localidades de Opaso y Bajada del Jagüel se encuentran en la provincia de Río Negro, al norte del poblado de Santa Rosa, en el área de Loma de la Salamanca (Hugo y Leanza, 2001), distante unos $290 \mathrm{~km}$ al sudeste de la región del Bajo de Añelo. Se trata de areniscas calcáreas y fangolitas con niveles biostromales con Ostrea alvarezii d'Orbigny. Contienen escasos foraminíferos, de regular a deficiente preservación, asignados tentativamente a Elphidium discoidale (d'Orbigny). Esta especie está comúnmente asociada a $P$. granosum en la perforación Tayra x-1 de la cuenca de Rawson y en la localidad tipo de la Formación Barranca Final, provincia de Río Negro (Malumián et al., 1998), pero también está en niveles aparentemente sin $P$. granosum, considerados paranenses, del Gran Bajo del Gualicho. En la plataforma continental actual, E. discoidale es indicadora de la Subprovincia Norpatagónica (Boltovskoy, 1976).

Otra localidad relativamente cercana se encuentra en el sudeste de la provincia de La Pampa, en Puesto Iriarte y El Surgente, a unos $400 \mathrm{~km}$ hacia el este de la región en estudio. Son calizas, evaporitas, areniscas y pelitas, que contienen Protelphidium tuberculatum (Parras et al., 2000; Visconti et al., 2003). Camacho (1967) extiende el mar Paranense hasta la localidad de Maquinchao, en la provincia de Río Negro, pero sin detallar sus fundamentos. Los afloramientos asignados a la transgresión Paranense en el sur de Mendoza (Pérez et al., 1996) son cercanos a los perfiles aquí estudiados, pero su carácter marino no ha sido documentado.

El género Protelphidium y morfotipos similares sugieren ambientes marinos hiposalinos muy someros, estuáricos o con influencia fluvial. La muy baja diversidad de la asociación en los perfiles Opaso y Bajada del Jagüel indicaría paleoambientes marinos marginales y salinidad anormal, sin descartar paleoambientes lacustres, que pueden o no haber estado comunicados con el mar paranense. El estudio sedimentológico de la sucesión de coquinas y areniscas que engloban el horizonte portador de Porosononion, sugiere ambientes marinos someros (Barrio, 1990a).

\section{Conclusiones}

Como parte de un estudio monográfico de la familia Elphidiidae del Cenozoico de la Argentina, se revisaron los ejemplares recuperados de un horizonte fangolítico intercalado entre coquinas, en los perfiles Opaso y Bajada del Jagüel (provincia del Neuquén, 
Argentina), sucesión asignada tanto a la Formación Roca (Paleoceno marino) como a la Formación Barranca de los Loros (Mioceno continental), según distintos autores. Los ejemplares, que fueron previamente identificados como Protelphidium sp. cf. P. hofkeri Haynes, se reasignan a Porosononion granosum (d'Orbigny).

En la Argentina, Porosononion granosum es una de las especies más características de la transgresión Paranense, de edad miocena media-tardía, donde ha sido tradicionalmente identificada bajo el nombre de Protelphidium tuberculatum o Protelphidium sp. cf. P. tuberculatum.

La presencia de Porosononion granosum en los perfiles Opaso y Bajada del Jagüel sugiere una vinculación con la transgresión Paranense, sustenta la asignación de la sucesión en cuestión a la Formación Barranca de los Loros, de edad miocena, y lleva a considerar retrabajados a los fósiles rocanenses asociados, tal como propuso Uliana (1979). Porosononion granosum conforma una asociación monoespecífica, que podría corresponder tanto a un paleoambiente marino marginal, probablemente hiposalino, como a un paleoambiente lacustre similar al propuesto para algunas sucesiones del Paranense del noroeste de la Argentina que también contienen foraminíferos.

Los ejemplares de la familia Elphidiidae del perfil Puesto sin Nombre, en el área de Sierras Blancas, provincia del Neuquén, se mantienen identificados como Protelphidium sp. cf. P. hofkeri, identificación bioestratigráficamente coherente con la asignación de las sedimentitas portadoras a la Formación Roca.

El reconocimiento de estas dos especies de Elphidiidae, Protelphidium sp. cf. P. hofkeri, de edad paleógena, en el perfil Puesto Sin Nombre, y Porosononion granosum, de edad neógena, en los perfiles Opaso y Bajada del Jagüel, asociadas a megafósiles rocanenses, sustenta la diferenciación propuesta por Groeber (1959) entre un Roca I, verdadero, y un Roca II, discordante y transgresivo. En este último, los megafósiles rocanenses serían retrabajados.

\section{Paleontología sistemática}

Las especies tradicionalmente asignadas al género Protelphidium en la Argentina, en particular Protelphidium cf. tuberculatum o " $P$ ". tuberculatum (d’Orbigny, 1846), característico de la transgresión
Paranense, y Protelphidium cf. hofkeri (Haynes, 1956), del Paleoceno de la Patagonia septentrional, tienen una posición genérica y/o específica que requiere revisión. A nivel genérico, la sistemática del grupo no está claramente establecida, en parte debido a la complejidad de las estructuras internas y a la variabilidad de la morfología externa.

Haynes (1956) definió el género Protelphidium, con Protelphidium hofkeri Haynes 1956, del Thanetiano de Inglaterra, como especie tipo. Puntualiza que la pared es radial y que difiere de Elphidium de Montfort, 1808 por la falta de procesos retrales, y de Elphidiella Cushman, 1936 por la falta de poros suturales. Loeblich y Tappan (1964) incluyeron a Nonionina tuberculata d'Orbigny, 1846, originalmente descrita del Mioceno de la cuenca de Viena, en el género Protelphidium, y extienden el biocrón de este género hasta el Plioceno. Al considerar a $N$. tuberculata sinónimo senior de Nonionina subgranosa Egger, 1857, especie tipo del género Porosononion Putrya en Voloshinova, 1958, este pasa a ser sinónimo junior de Protelphidium.

Hansen y Lykke-Andersen (1976) reconocen, mediante moldes internos, un canal umbilical espiral con comunicación a espacios interloculares en topotipos de Nonionina subgranosa Egger, considerada sinónima de Nonionina tuberculata por Marks (1951) y Loeblich y Tappan (1964), y especie tipo del género Porosononion, todos taxones con aberturas múltiples tanto interiomarginales como areales. El canal espiral es el carácter constante que para Hansen y Likke-Andersen (1976) define al género Elphidium entre las formas planoespirales, por lo que incluyen Nonionina tuberculata en el género Elphidium. Por el contrario, al no reconocer un canal espiral umbilical en topotipos de Protelphidium hofkeri y no otorgar al carácter óptico de la pared un significado supraespecífico, consideran a esta especie perteneciente al género Nonion Montfort, 1808, y consecuentemente no reconocen a Protelphidium como género válido.

Banner y Culver (1978) redescriben y enmiendan el género Protelphidium y su especie tipo, P. hofkeri, y destacan su restricción al Paleógeno, descartando la sinonimia de Porosononion con Protelphidium, como fue propuesto en Loeblich y Tappan (1964). Proponen el género Haynesina para formas cuartarias.

Papp y Schmid (1985), al revisar el material original de d'Orbigny del Mioceno de la cuenca de Viena, en el recipiente que corresponde a Nonionina 
tuberculata se encuentran con ejemplares que carecen de tubérculos umbilicales como los de la ilustración y descripción de d'Orbigny (1846) y que, por el contrario, son profundamente umbilicados como Melonis pompilioides (Fichtel y Moll, 1798), especie a la cual asignan los ejemplares del recipiente, mencionando, además, que Loeblich y Tappan (1964) incluyeron estas formas en Protelphidium, aparentemente confundiéndolo con Nonionina granosa. Papp y Schmid (1985) asignan esta especie a Elphidium (Porosononion) granosum, al tiempo que ilustran su canal espiral con una foto de Hansen. Utilizan esta categoría subgenérica para reunir las especies de un grupo neógeno ampliamente distribuido con características morfológicas fácilmente discernibles: aberturas y forámenes múltiples, carecen de pontículos y procesos retrales, y poseen espacios interloculares marginalmente ornamentados; comprenden camaritas separadas de la cámara principal por placas umbilicales y principalmente un canal umbilical espiral. Este último es considerado por Hansen y Lykke-Andersen (1976) la característica determinante del género Elphidium, criterio seguido por otros autores (e.g., Jorissen, 1988). Hottinger et al. (2001) como medida provisoria, consideran válido el género Porosononion para incluir estas formas en cuestión, criterio diferente al de Loeblich y Tappan (1987), quienes consideran a Porosononion sinónimo de Cribroelphidium Cushman y Brönnimann, 1948. Sobre la base de la revisión de Papp y Schmid (1985) y el criterio de Hottinger et al. (2001), las formas argentinas que habían sido asignadas a Protelphidium tuberculatum por su identificación con la ilustración de esta especie en Loeblich y Tappan (1964), se transfieren a Porosononion granosum.

Loeblich y Tappan (1987) restringen el género Protelphidium a las formas paleógenas sin espacios intercamerales y con una abertura interiomarginal ecuatorial en forma de ranura, y lo incluyen en la familia Nonionidae. Según estos autores, el género se reconoce desde el Daniano hasta el Oligoceno en Inglaterra, Francia, Libia y la Unión Soviética.

Voltski et al. (2015) asignan Nonion? niveum Lafrenz, 1963, especie de edad pliocena-reciente del norte de Europa y Groenlandia, al género Protelphidium, enmendando este último género y extendiendo su biocrón al Reciente, sin registros por un gran intervalo desde la extinción de Protelphidium hofkeri en el Paleógeno. Los autores reconocen en Nonion? niveum características morfológicas comparables a las de $P$. hofkeri. Describen un canal espiral umbilical, determinado por camarillas foliares en la región umbilical. Consideran a Protelphidium como parte de los elfidiidos inferiores, integrado por géneros de periferia redondeada y con puentes escasos o ausentes, como Haynesina y Cribroelphidium, en contraposición al género Elphidium, más complejo morfológicamente. Describen para estos elfidiidos inferiores un canal espiral umbilical, formado por camarillas foliares interconectadas. Suponen que casi indudablemente Protelphidium hofkeri tenía un canal espiral umbilical de estas características, aunque señalan la necesidad de revisar el material tipo de la especie. Indican como importante carácter diferenciante de Haynesina de Protelphidium, las aberturas suplementarias que conectan la cavidad cameral principal con los espacios intraseptales interloculares, diferencia ya mencionada por Banner y Culver (1978).

\section{Porosononion granosum (d'Orbigny, 1846)} Fig. 5 A-J; Fig. 6 A-K.

1846. Nonionina granosa d'Orbigny, p. 110, lám. 5, figs. 19, 20.

1968. Elphidium selseyense Heron-Allen y Earland. Closs y Madeira, p. 232, lám. 1, fig. 9. 1972. Protelphidium tuberculatum (d'Orbigny). Malumián, p. 116, lám. 4, figs. 4a, b. 1977. Protelphidium tuberculatum d'Orbigny. Zabert in Zabert y Herbst, p. 144, lám. 1, fig. 4. 1978. "Protelphidium" tuberculatum (d'Orbigny). Malumián, p. 168.

1978. Elphidium cf. tuberculatum (d'Orbigny). Sprechmann, p. 60, lám. 5, figs. 7-8 .

1980. Protelphidium tuberculatum (d'Orbigny).

Becker y Bertels, p. 319, lám. 4, fig. 3.

1981. ?Elphidium gunteri, sensu Boltovskoy, p. 353, lám. 2, fig. 1 (non E. gunteri Cole, 1931), non figura 2.

1984. "Protelphidium" cf. tuberculatum (d'Orbigny, 1846). Malumián y Náñez, p. 496, lám. 2, fig. 25-26.

Descripción: Conchilla planoespiral, involuta, contorno entero a levemente lobulado, biconvexa, periferia subredondeada, raramente subaguda. Siete y media a once cámaras en la última vuelta, generalmente 8-10, que aumentan gradualmente de tamaño. Suturas intercamerales curvadas, incisas 


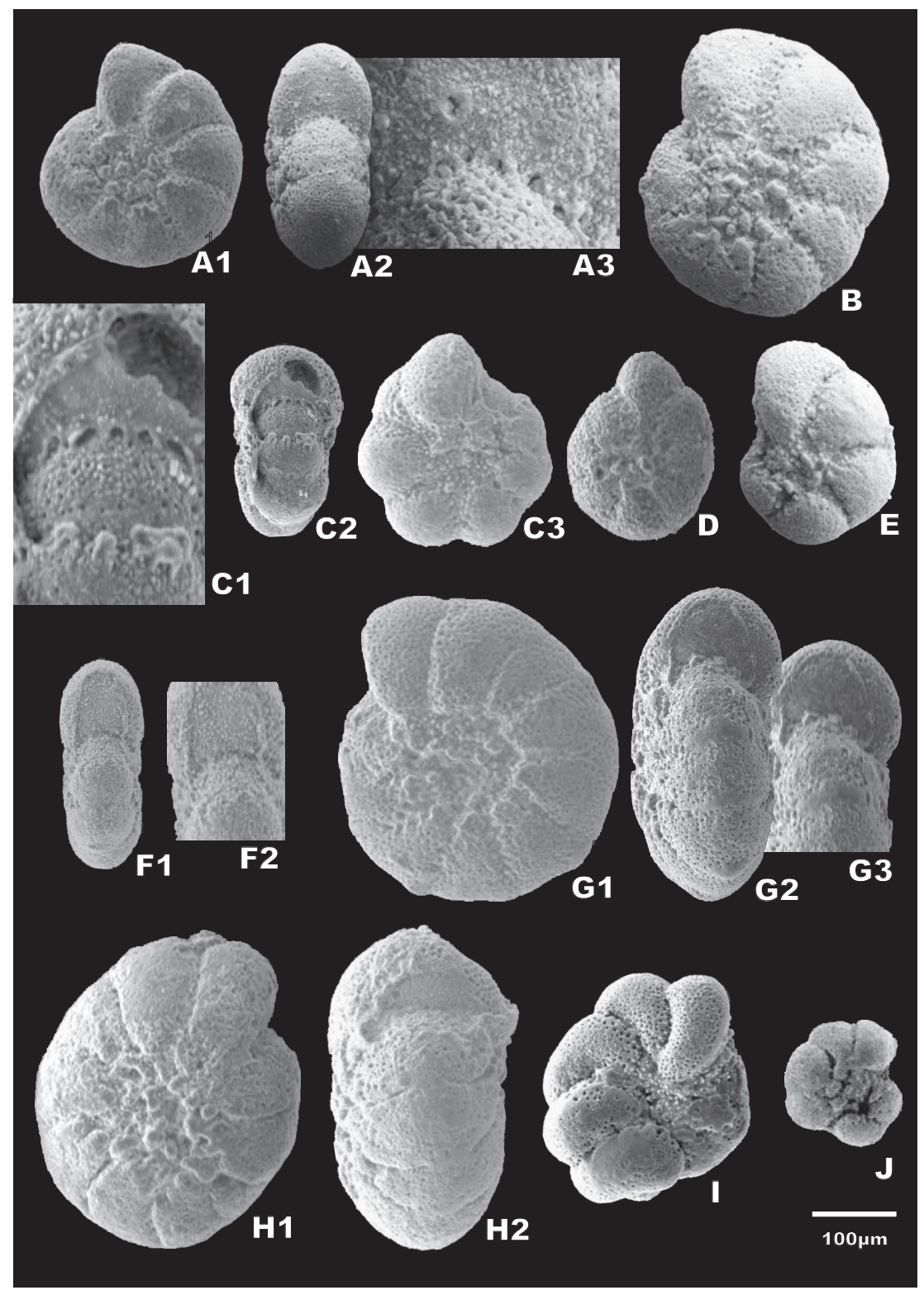

FIG. 5. Porosononion granosum (d'Orbigny, 1846). Ejemplares provenientes de los perfiles Opaso y Bajada del Jagüel, provincia del Neuquén. La barra equivale a $100 \mu \mathrm{m}$. A. A1, A2, A3. Vista lateral, periférica y detalle que muestra los forámenes múltiples, en forma de poros de posición interiomarginal y un foramen en posición areal. Perfil Opaso, muestra OP39. SEGEMAR 2993; B. Vista lateral. Perfil Opaso, muestra OP39. SEGEMAR 2994; C. C1, C2. Vista periférica y detalle de forámenes múltiples interiomarginales; C3. vista lateral. Perfil Bajada del Jagüel, muestra 8R (Barrio, 1989,1990a). SEGEMAR 2995; D. Vista lateral de un ejemplar con fuerte recristalización y disolución. Perfil Opaso, muestra OP39. SEGEMAR 2996; E. Ejemplar con escasas cámaras, contorno ovalado, en el que se preservan algunas perforaciones gruesas y tubérculos en la región umbilical. Perfil Opaso, muestra OP39. SEGEMAR 2997; F. Ejemplar comprimido lateralmente, recristalizado, con forámenes múltiples interiomarginales. Perfil Bajada del Jagüel, muestra 8R (Barrio, 1989,1990a). SEGEMAR 2998; G. G1, G2, G3. Vista lateral, periférica y detalle, que muestra la pared con perforaciones gruesas, región umbilical donde se ha desprendido el relleno de grandes tubérculos, suturas limbadas, imperforadas sobre la periferia, y forámenes múltiples interiomarginales. Perfil Opaso, muestra OP39. SEGEMAR 2999; H. H1, H2. Ejemplar con fuerte disolución, y suturas limbadas, imperforadas, sobre la periferia. Perfil Opaso, muestra OP39. SEGEMAR 3000; I-J. Ejemplares de crecimiento anómalo. Perfil Opaso, muestra OP39. SEGEMAR 3001-3002. 


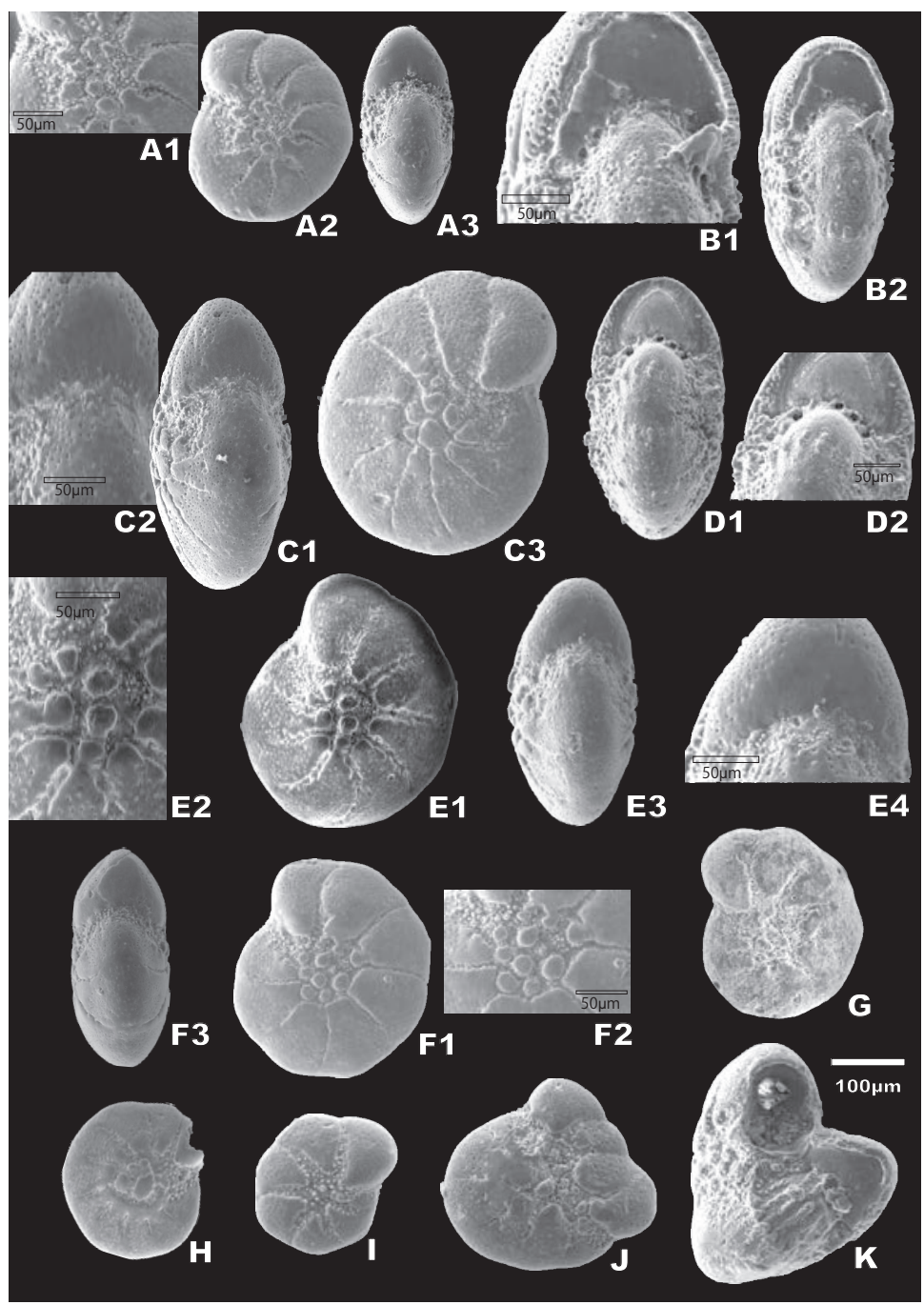

FIG. 6. Porosononion granosum (d’Orbigny, 1846). Todos ejemplares de la perforación Tayra x-1, cuenca de Rawson, plataforma continental argentina, excepto figura G, de la localidad tipo de la Formación Barranca Final, provincia de Río Negro, Argentina. La barra equivale a $100 \mu \mathrm{m}$. A. A1, A2, A3. Vista lateral y detalle; pared con perforaciones gruesas, extremos umbilicales de las cámaras imperforados, suturas excavadas y parcialmente abiertas en el tramo cercano al ombligo, y tubérculos grandes acompañados por tubérculos pequeños en la región umbilical. Vista periférica con la base de la cara apertural cubierta por tubérculos y pústulas y una abertura visible de posición areal, en forma de poro proyectado sobre una extensión tubular. Pozo Tayra x-1, 450-60 mbbp. SEGEMAR 3003; B. B1, B2. Vista periférica y detalle; forámenes múltiples interiomarginales, aparentemente también con un foramen en posición subareal, y restos de la cara apertural anterior replegada en su base, con los forámenes en los extremos de estas extensiones tubulares. Pozo Tayra x-1, 450-60 mbbp. SEGEMAR 3004; C. C1, C2. Vista periférica y detalle; la cara apertural imperforada, sin abertura visible; C3. vista lateral. Pozo Tayra x-1, 560-70 mbbp. SEGEMAR 3005; D. D1, D2. Vista periférica; ejemplar con forámenes múltiples, en forma de poros de posición interiomarginal. Pozo Tayra x-1, 450-60 mbbp. SEGEMAR 3006; E. E1, E2. Vista lateral y detalle de la región umbilical; E3, E4. vista periférica y detalle del área apertural. Pozo Tayra x-1, 480-90 mbbp. SEGEMAR 3007; F. F1, F2. Vista lateral y detalle; F3. vista periférica con última cámara conservada, abertura no visible, pared perforada, suturas imperforadas, incisas, al ras sobre la periferia. Pozo Tayra x-1, 600-610 mbbp. SEGEMAR 3008; G. Vista lateral. Formación Barranca Final, localidad tipo. SEGEMAR 3009; H. Vista lateral de un ejemplar con los extremos umbilicales de las cámaras en parte fundidos en una banda imperforada periumbilical, y suturas intercamerales hendidas hasta cerca de la periferia. Pozo Tayra x-1, 490-500 mbbp. SEGEMAR 3010; I. Ejemplar con escaso desarrollo de tubérculos grandes en la región umbilical. Pozo Tayra x-1 460-70 mbbp. SEGEMAR 3011; J. Ejemplar con crecimiento anormal. Pozo Tayra x-1, 530-40 mbbp. SEGEMAR 3012; K. Ejemplares siameses (twin specimens). Pozo Tayra x-1, 450-60 mbbp. SEGEMAR 3013. 
y ensanchadas hacia la región umbilical, a veces bordeadas por una hilera de tubérculos, la cual le da un aspecto crenulado a los bordes de la sutura; hacia la periferia se hacen limbadas e imperforadas, a veces levemente deprimidas. Región umbilical amplia, rellena por tubérculos grandes y otros más pequeños, romos, de contornos irregulares. Pared densamente perforada, excepto en la cara apertural, suturas, bordes y extremos umbilicales de las cámaras, estos últimos en ocasiones fundidos con los tubérculos de la región umbilical. Abertura no visible, base de la cara apertural cubierta generalmente por pequeños gránulos, a veces puntiagudos. En los septos previos, se observan forámenes múltiples en forma de poros de posición interiomarginal, con uno o pocos poros de posición areal.

Observaciones: La descripción previa se basa en material de la perforación Tayra x-1, muestra 45060 mbbp., de muy buena preservación. El material del pozo Tayra está compuesto en general de conchillas biconvexas y secundariamente por conchillas más comprimidas y aplanadas lateralmente. El contorno es generalmente entero, apenas lobulado en las últimas cámaras; menos frecuentes son los ejemplares de contorno lobulado. Las suturas son en su mayoría radiales y suavemente curvadas y en algunos ejemplares recurvadas hacia atrás. La abertura no es visible, en pocos casos se reconoce un poro areal proyectado en un túbulo (Fig. $6 \mathrm{~A} 3$ ), y en algunos se intuyen aberturas interiomarginales múltiples pero no se ven con claridad. En un ejemplar, se observa que la cara septal se repliega en su base y da lugar a los forámenes (Fig. 6B).

Las conchillas recuperadas del perfil Opaso (muestra OP39), de preservación pobre, están con frecuencia vacías pero con la pared fuertemente corroída. Las diferencias con los ejemplares del pozo Tayra $\mathrm{x}-1$ son las siguientes: a) la mayoría de las conchillas con la periferia ampliamente redondeada a subredondeada, b) región umbilical generalmente aplanada, c) contorno lobulado y cámaras más infladas, d) en promedio un menor número de cámaras en la última vuelta, entre 6 y 10 , frecuentemente 7 . Se las identifica con P. granosum por las características aperturales, consistente en forámenes múltiples en forma de poros de posición interiomarginal, ocasionalmente con algún poro de posición areal, la pared con perforaciones gruesas, que llegan a verse en algunos ejemplares con lupa binocular, las suturas hendidas hasta la mitad de su recorrido hacia la periferia, al ras y limbadas e imperforadas sobre la periferia, y la región umbilical cubierta por tubérculos grandes, romos. Estos a veces tienden a formar una orla periumbilical y parecen estar vinculados con los extremos umbilicales imperforados de las cámaras, como también se aprecia en algunas conchillas provenientes del pozo Tayra x-1. El relleno umbilical con frecuencia falta total o parcialmente en las conchillas del perfil Opaso, pues se ha fragmentado o perdido, probablemente por efecto de la disolución (Fig. 5G).

Porosononion granosum, según la ilustración de Papp y Schmid (1985), es muy parecido al material argentino pero tiene poros más grandes y grandes forámenes areales con reborde, alrededor de 12 en la ilustración, y no muestra claramente los de la base de la cámara. En el material argentino, en raras ocasiones se observa un foramen areal y falta corroborar la existencia de los canales espirales.

Esta especie, ampliamente difundida por la transgresión Paranense, ha sido usualmente nominada como Protelphidium tuberculatum en la Argentina. En un principio, ilustrada por Closs y Madeira (1968) como Elphidium selseyense para el sur del Brasil, con el comentario válido a la fecha de que llama la atención que no esté representada en la fauna actual. Fue registrada en la Formación Paraná por Pisetta (1968) e ilustrada para la cuenca del Salado, subsuelo de la provincia de Buenos Aires (Malumián, 1970, 1972), asignaciones coherentes con la ilustración de la especie en Loeblich y Tappan (1964). Malumián (1978) la destaca como la especie que caracteriza a una de las asociaciones de foraminíferos de la Argentina, pero observa su asignación genérica como "Protelphidium", y puntualiza que Banner y Culver (1978) consideran al género Protelphidium restringido al Paleógeno, y que la especie de d'Orbigny debería entonces referirse al género Porosononion. Para la cuenca de Pelotas, Brasil, fue ilustrada por Boltovskoy et al. (1983), como Protelphidium sp., en horizontes de edad miocena, y citada por Madeira Falcetta y Thiesen (1988), para capas de edad tortoniana o más jóvenes. Herbst y Zabert (1987) y Marengo (2000, 2006) reconocen su amplia distribución en la cuenca Chaco-Paranense. La especie se reconoció también en la cuenca del Colorado, tanto en el sector emergido (Malumián y Náñez, 1984; Malumián et al., 1998; Busteros et al., 1998; Parras et al., 2000; Guler et $a l ., 2002)$ como en la plataforma continental, en 
la perforación Puelche, donde nomina una zona de foraminíferos (Becker y Bertels, 1980), así como en la cuenca de Península Valdés (Masiuk et al., 1976; Caramés et al., 2004).

Porosononion granosum se reconoce con identificación tentativa en el Mioceno de la Amazonia colombiana y peruana, de ambiente estuarino (Boonstra et al., 2015). Se distribuye en el Neógeno, Cuaternario y Reciente europeo (e.g., Brodniewicz, 1972; Jorissen, 1987; Poignant et al., 2000). En el Paratethys central, se reconoce desde el Oligoceno tardío al fin del Sarmatiano (Cicha et al., 1998), piso que se extiende en la parte más alta del Serravaliano, o sea, Mioceno medio cuspidal, donde la especie nomina una biozona (Harzhauser y Piller, 2004). Gross et al. (2007) lo citan para ambientes someros, con salinidades bajas o fuertemente variables, y mencionan que en ambientes fangosos los ejemplares son de menor tamaño y paredes más finas, aumentando en tamaño y grosor de la pared con el aumento en el contenido de arena.

\section{Protelphidium sp. cf. P. hofkeri Haynes, 1956} Fig. 7, A-J

cf. Protelphidium hofkeri Haynes, 1956. Contrib. Cushman Found. Foram. Res. 7, parte 3 , p. 86, lám. 16, fig. 9-9c; lám. 18, fig. 3 .

1965. Protelphidium cf. hofkeri Haynes. Bertels, p. 179, lám. 7, figs. 11 a-b.

1965. Protelphidium sublaeve (ten Dam).

Bertels, p. 179, lám. 7, figs. 10 a-b.

1966. Protelphidium hofkeri Haynes. Méndez, p. 148, lám. 3, fig. 2a-b.

1967. Protelphidium hofkeri Haynes. Masiuk, p. 225, lám. 1, figs. 4a-b.

1995. Protelphidium hofkeri Haynes. Malumián y Caramés, p. 102, lám. 2, fig. 9 a-b.

Descripción: Conchilla planoespiral, involuta, contorno suboval a subcircular, entero a suavemente lobulado, biconvexa, periferia generalmente subaguda, a veces redondeada. Cinco y media a nueve cámaras en la última vuelta, más frecuentemente 6 , que al crecer especialmente en altura, producen el contorno suboval de la conchilla. Suturas intercamerales curvadas, incisas y cubiertas o bordeadas por tubérculos en su tramo más cercano a la región umbilical, haciéndose al ras hacia la periferia. Región umbilical aplanada, a veces levemente deprimida, rellena por tubérculos, por lo general puntiagudos. Pared finamente perforada. Abertura no visible, base de la cara apertural cubierta por tubérculos. Foramen interiomarginal, en forma de ranura baja.

Observaciones: La descripción está basada en los ejemplares del perfil Puesto Sin Nombre, muestra PSN 58. Protelphidum hofkeri, descrito originalmente del Paleoceno de Inglaterra, y especie tipo del género Protelphidium, presenta su región umbilical y parte inferior de la cara apertural cubierta por tubérculos puntiagudos, y una abertura o foramen interiomarginal. Haynes (1956) describe que los forámenes de Protelphidium hofkeri son variables, a veces una ranura única, de diferente longitud en diferentes ejemplares, en otros, puede haber hasta tres o más ranuras. Revisiones posteriores indican una única abertura en forma de ranura interiomarginal ecuatorial (Hansen y Likke-Andersen, 1976; Banner y Culver, 1978), criterio que siguen Loeblich y Tappan (1987), describiendo para el género una abertura primaria como un arco bajo, estrecho, interiomarginal y ecuatorial.

Los ejemplares del perfil Puesto Sin Nombre son similares a $P$. hofkeri, pero tienen perforaciones de la pared más finas, el contorno en general más ovalado, y número de cámaras en la última vuelta algo menor, en comparación con los ejemplares topotípicos de $P$. hofkeri ilustrados por Banner y Culver (1978). El número de cámaras en la última vuelta en $P$. hofkeri, según Haynes, es de 8 a 10, según Hansen y Likke-Andersen (1976) es de 6-7, mientras Banner y Culver (1978) indican 7 a 10.

Los ejemplares neuquinos son similares al ilustrado para la Formación Salamanca, cuenca del Golfo de San Jorge, por Malumián y Caramés (1995) y en este trabajo (Fig. 7J), que tiene un foramen en forma de ranura, interiomarginal, y contorno oval. Ejemplares de P. hofkeri de la misma formación ilustrados por Méndez (1966) y por Masiuk (1967) muestran también tubérculos puntiagudos en la región umbilical. Un ejemplar depositado por este último autor en la colección del SEGEMAR parece también tener un foramen en forma de ranura o arco bajo, en posición interiomarginal.

La ilustración de Bertels (1965) del ejemplar de $P$. cf. hofkeri del perfil tipo de la Formación Roca es un dibujo que muestra forámenes múltiples interiomarginales, característica que lo acercaría a Elphidium granosum. La observación expeditiva de ejemplares depositados por Bertels en la colección 


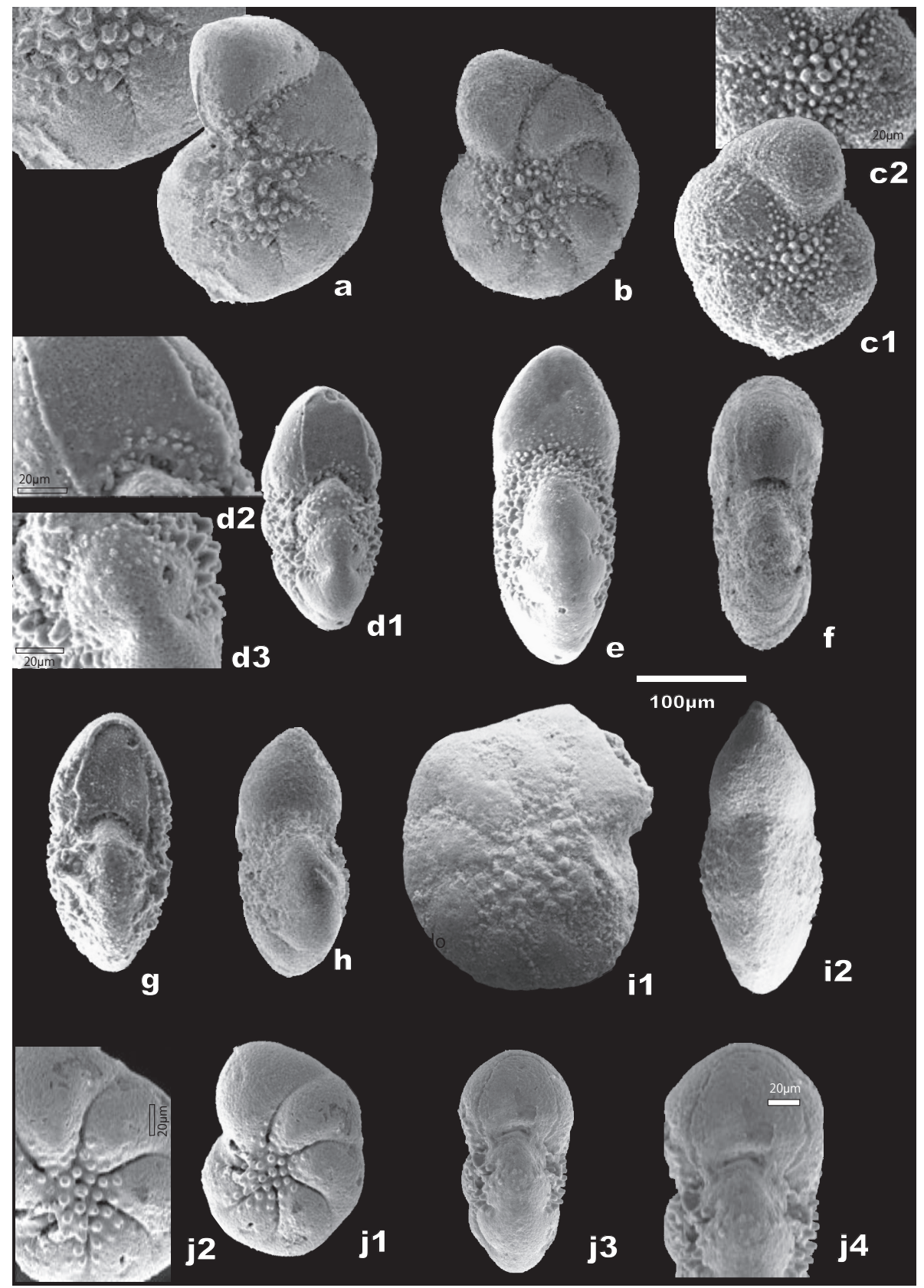

FIG. 7. Protelphidium sp. cf. P. hofkeri Haynes, 1956. La barra equivale a $100 \mu \mathrm{m}$. A-H. Perfil Puesto sin Nombre, muestra PSN 58, Formación Roca, Paleógeno; A. Vista lateral y detalle que muestra los finos poros de la pared. SEGEMAR 3014; B. Vista lateral. SEGEMAR 3015; C. C1, C2. Vista lateral y detalle de las pústulas umbilicales. SEGEMAR 3016; D. D1. vista periférica; D2, D3. detalle del foramen y de la pared finamente perforada, incluso en la pared septal, y pústulas umbilicales. SEGEMAR 3017; E. Vista periférica. SEGEMAR 3018; F-G. Vistas periféricas; forámenes en forma de ranura de posición interiomarginal. SEGEMAR 3019-3020; H. Vista periférica. SEGEMAR 3021; I. I1, I2. Vistas lateral y periférica de un ejemplar retrabajado en el Mioceno. Perfil Opaso, muestra OP44, Formación Barranca de los Loros. SEGEMAR 3022; J. J1, J2, J3, J4. Vistas lateral y periférica con tubérculos puntiagudos en la región umbilical y foramen interiomarginal en forma de ranura. Ejemplar de la Formación Salamanca, provincia de Chubut, vista lateral previamente ilustrada por Malumián y Caramés (1995). SEGEMAR 1759. 
de Micropaleontología de la Facultad de Ciencias Exactas y Naturales de la Universidad de Buenos Aires, sugiere más similitud con $P$. hofkeri por la morfología general, pero no se pudieron apreciar las características aperturales.

Ejemplares de la Formación Roca de la localidad de Cerros Bayos, provincia de La Pampa, se incluyen en esta especie, aunque presentan algunas diferencias morfológicas, como las suturas con algunas ramificaciones en algunos ejemplares pampeanos.

Protelphidium cf. hofkeri, del perfil Puesto sin Nombre, se diferencia de $P$. granosum principalmente por la porosidad más fina, el foramen interiomarginal simple, en forma de ranura, ausencia de tubérculos grandes, de forma irregular y romos en el área umbilical, y tiene, en cambio, tubérculos o pústulas más pequeñas y puntiagudas. El número de cámaras en la última vuelta es en promedio menor, cámaras no infladas, la conchilla de contorno generalmente suboval y periferia subaguda en los ejemplares de la Formación Roca, en comparación con los ejemplares ahora reasignados a $P$. granosum, provenientes de los perfiles Opaso y Bajada del Jagüel. La asociación del perfil Puesto Sin Nombre presenta menor cantidad de ejemplares con anormalidades.

Es similar a Protelphidium sp. 1 y Protelphidium sp. 2, del Eoceno de las cuencas de Hampshire y de París (Murray y Wright, 1974), por el contorno lateral oval y la periferia subaguda, diferenciándose principalmente en el mayor desarrollo de relleno pustuloso umbilical del material neuquino. Estos autores mencionan para las especies de Protelphidium del Eoceno y Oligoceno, aberturas interiomarginales dadas por hileras de poros, o una ranura con ornamentación de tubérculos que sugieren una hilera de poros. Protelphidium sp. 1 proviene del Bartoniano de Inglaterra. Protelphidium sp. 2 es ilustrado para el Bartoniano de la cuenca de París, pero en el texto solo es citado para el Ypresiano de Inglaterra.

Protelphidium niveum, del Plioceno a Reciente del norte de Europa, se diferencia de $P$. sp. cf. $P$. hofkeri, por la abertura múltiple, consistente de 2 a 5 poros de posición interiomarginal, y la cara apertural con poros presentes raramente.

Protelphidium hofkeri fue descrito originalmente del Thanetiano de Inglaterra (Haynes, 1956; Banner y Culver, 1978). También es mencionado para el Eoceno medio y superior de la cuenca de París y, con dudas, del Paleoceno de Suecia (Haynes, 1956).

\section{Agradecimientos}

Se agradece especialmente a C. Barrio por las muestras del perfil Bajada del Jagüel. A F. Aceñolaza, A. Ardolino, M. Franchi e I. Gavriloff, por sus valiosos comentarios y bibliografía. A M. Marchant y dos revisores anónimos por sus acotaciones que contribuyeron a mejorar el manuscrito original. Al SEGEMAR (Servicio Geológico Minero Argentino), donde se ha realizado el estudio. Trabajo parcialmente financiado por el proyecto CONICET PIP 0281.

\section{Referencias}

Abu-Zied, R.H.; Keatings, K.W.; Flower, R.J. 2007. Environmental controls on foraminifera in Lake Qarum, Egypt. Journal of Foraminiferal Research 37 (2): 136-149.

Aceñolaza, F.G. 2000. La Formación Paraná (Mioceno medio): estratigrafía, distribución regional y unidades equivalentes. In El Neógeno de Argentina (Aceñolaza, F.; Herbst, R.; editores). Serie Correlación Geológica 14: 9-28.

Aceñolaza, F.G. 2007. Sinopsis estratigráfica de la Mesopotamia. In Geología y Recursos Geológicos de la Mesopotamia Argentina. Serie Correlación Geológica 22: 43-112.

Anadón, P. 1989. Los lagos salinos interiores (atalásicos) con faunas de afinidad marina del Cenozoico de la Península Ibérica. Acta Geologica Hispanica 24 (2): 83-102.

Andreis, R.R.; Iñíguez-Rodríguez, A.M.; Lluch, J.J.; Sabio, D.A. 1974. Estudio sedimentológico de las formaciones del Cretácico Superior del área del Lago Pellegrini (Provincia de Río Negro, República Argentina). Revista de la Asociación Geológica Argentina 29 (1): 85-104.

Angulo, R.J.; Casamiquela, R.M. 1982. Estudio estratigráfico de las unidades aflorantes en los acantilados de la costa norte del golfo San Matías (Río Negro y extremo austral de Buenos Aires) entre los meridianos 62³0’ W y 6430' W. Mundo Ameghiniano 2: 20-73.

Aramayo, S. 1987. Plohophorus aff. figuratus (Edentata, Glyptodontidae) en la Formación Río Negro (Mioceno tardío-Plioceno), provincia de Río Negro, Argentina. Importancia bioestratigráfica. In Congreso Geológico Argentino, No. 10, Actas 3: 171-174. San Miguel de Tucumán.

Ardolino, A.; Franchi, M. 1997. Geología. In Geología y Recursos Minerales del Departamento Añelo. Provincia del Neuquén. República Argentina (Ardolino, A.; Franchi, M.; editores). Dirección Nacional del 
Servicio Geológico, Anales 25 y Dirección Provincial de Minería, Boletín 3: 9-106.

Ardolino, A.; Franchi, M.; Fauqué, L. 1995. Carta geológica de la provincia del Neuquén, departamento Añelo. Dirección Provincial de Minería, Servicio Geológico Neuquino, y Secretaría de Minería de la Nación, Dirección Nacional del Servicio Geológico. Argentina.

Ballent, S.C.; Carignano, A.P. 2008. Morphological abnormalities in Late Cretaceous and early Paleocene foraminifer tests (northern Patagonia, Argentina). Marine Micropaleontology 67: 288-296.

Ballent, S.; Concheyro, A.; Náñez, C.; Pujana, I.; Lescano, M.; Carignano, A.; Caramés, A.; Angelozzi, G.; Ronchi, D. 2011. Microfósiles Mesozoicos y Cenozoicos. Geología y Recursos Naturales de la Provincia del Neuquén (Leanza, H.; Arregui, C.; Carbone, O.; Danieli, J.C.; Vallés, J.M.; editores). In Congreso Geológico Argentino, No. 18, Relatorio: 489-528. Neuquén.

Banner, F.T.; Culver, S.J. 1978. Quaternary Haynesina n.gen. and Paleogene Protelphidium Haynes; their morphology, affinities and distribution. Journal of Foraminiferal Research 8: 177-207.

Barrio, C.A. 1989. Sedimentology of the Malargüe Group (Upper Cretaceous-Lower Tertiary), Neuquén Basin, Western Argentina. Ph.D. thesis (Unpublished). University of South Carolina: 180 p. Columbia.

Barrio, C.A. 1990a. Late Cretaceous-Early Tertiary sedimentation in a semi-arid foreland basin (Neuquen Basin, western Argentina). Sedimentary Geology 66: 255-275

Barrio, C.A. 1990b. Paleogeographic control of Upper Cretaceous tidal deposits, Neuquén Basin, Argentina. Journal of South American Earth Sciences 3 (1): 31-49.

Becker, D.; Bertels, A. 1980. Micropaleontología de la secuencia Terciárica de la Perforación Puelche (Margen Continental Argentino). In Congreso Argentino de Paleontología y Bioestratigrafía, No. 2, y Congreso Latinoamericano de Paleontología, No. 1, Actas 2: 315-333. Buenos Aires.

Bellosi, E.S. 1995. Paleogeografía y cambios ambientales de la Patagonia central durante el Terciario medio. Boletín de Informaciones Petroleras 44: 50-83.

Bertels, A. 1965. Micropaleontología del Paleoceno de General Roca (Provincia de Río Negro). Revista Museo La Plata, n.s., Paleontología 23 (4): 125-184.

Bertels, A. 1969. Estratigrafía del límite Cretácico-Terciario en Patagonia Septentrional. Asociación Geológica Argentina, Revista 24 (1): 41-54.

Bertels, A. 1975. Bioestratigrafía del Paleoceno marino en la provincia de Chubut, República Argentina. In
Congreso Argentino de Paleontología y Bioestratigrafía, No. 1, Actas 2: 271-316. Tucumán.

Bertels, A. 1979. Paleobiogeografía de los foraminíferos del Cretácico superior y Cenozoico de América del Sur. Ameghiniana 16 (3-4): 273-356.

Bertels, A. 1980. Estratigrafía y foraminíferos (Protozoa) bentónicos del límite Cretácico-Terciario en el área tipo de la Formación Jagüel, Provincia de Neuquén, República Argentina. In Congreso Argentino de Paleontología y Bioestratigrafía, No. 2 y Congreso Latinoamericano de Paleontología, No. 1, Actas 2: 47-91. Buenos Aires.

Bertels, A.; Zabert, L. 1980. Microfauna del Grupo Santa María (Terciárico superior) en las provincias de Catamarca y Tucumán, República Argentina. In Congreso Argentino de Paleontología y Bioestratigrafía, No. 2, y Congreso Latinoamericano de Paleontología, No. 1, Actas 3: 67-73. Buenos Aires.

Bertolino, S.R.A.; Poiré, D.G.; Carignano, C. 2000. Primer registro de sedimentitas marinas terciarias aflorantes en las Sierras Pampeanas de Córdoba, Argentina. Asociación Geológica Argentina, Revista 55 (1-2): 121-124.

Boltovskoy, E. 1976. Distribution of Recent Foraminifera of the South American Region. In Foraminifera (Hedley, R.H.; Adams, C.G.; editors). Academic Press 2: 171-235. London.

Boltovskoy, E. 1981. Perforación Gil 1, Provincia de Buenos Aires (Foraminíferos, edad, paleoambiente). Ameghiniana 4: 339-362.

Boltovskoy, E. 1991. Ihering's hypothesis in the light of foraminiferological data. Lethaia 24: 191-198.

Boltovskoy, E.; Thiesen, Z.V.; Madeira-Falcetta, M. 1983. Foraminíferos de cuatro perforaciones de la planicie costera de Río Grande Do Sul (Brasil). Pesquisas 15: 127-149.

Boonstra, M.; Ramos, M.I.F.; Lammertsma, E.I.; Antoine, P.-O.; Hoorn, C. 2015. Marine connections of Amazonia: Evidence from foraminifera and dinoflagellate cysts (early to middle Miocene, Colombia/Peru). Palaeogeography, Palaeoclimatology, Palaeoecology 417: 176-194.

Bossi, G.E.; Gavriloff, I.J.C. 1998. Terciario. Estratigrafía, Bioestratigrafía y Paleogeografía. In Geología de Tucumán (Gianfrancisco, M.; Puchulu, M.E.; Durango de Cabrera, J.; Aceñolaza, G.F.; editores). Colegio de Graduados en Ciencias Geológicas de Tucumán, Publicación Especial: 1-23.

Boudreau, R.E.A.; Patterson, R.T.; Dalby, A.P.; McKillpo, W.B. 2001. Non-marine occurrence of the foraminifera Cribroelphidium gunteri in northern lake Winnipegosis, 
Manitoba, Canada. Journal of Foraminiferal Research 31 (2): 108-119.

Brodniewicz, I. 1972. Pleistocene foraminifers of the area of the lower Vistula river (northern Poland). Acta Palaeontologica Polonica 17 (4): 423-525.

Brotzen, F. 1948. The Swedish Paleocene and its foraminiferal fauna. Sveriges Geologiska Undersökning 42 (2): 1-140.

Busteros, A.; Giacosa, R.; Lema, H. 1998. Hoja Geológica 4166-IV Sierra Grande. Instituto de Geología y Recursos Minerales, Servicio Geológico Minero Argentino, Boletín 241: 1-75.

Camacho, H.H. 1967. Las transgresiones del Cretácico Superior y Terciario de la Argentina. Asociación Geológica Argentina, Revista 22 (4): 253-280.

Cann, J.H.; De Deckker, P. 1981. Fossil Quaternary and living foraminifera from athalassic (non-marine) saline lakes, Southern Australia. Journal of Paleontology 55 (3): 660-670.

Caramés, A.; Malumián, N.; Náñez, C. 2004. Foraminíferos del Paleógeno del Pozo Península Valdés (PV.es-1), Patagonia septentrional, Argentina. Ameghiniana 41 (3): 461-474.

Carignano, A.P.; Garrido, A. 2006. Microfósiles calcáreos de la Formación Allen (Cretácico superior) en la localidad de Auca Mahuevo, provincia del Neuquén, Argentina. In Congreso Argentino de Paleontología y Bioestratigrafía, No. 9, Resúmenes: 216. Córdoba.

Carignano, A.P.; Ballent, S. 2009. Microfósiles (Foraminifera, Ostracoda) y su respuesta a las variaciones paleoambientales. Un ejemplo en la Formación Allen (Cretácico Superior), Cuenca Neuquina, Argentina. Ameghiniana 46 (2): 307-320.

Casadío, S.; Concheyro, A. 1992. Facies y ambientes de sedimentación en el límite Cretácico-Terciario de La Pampa, Argentina. In Congreso Geológico de España, No. 3 y Congreso Latinoamericano de Geología, No. 7, Actas 4: 30-34. Salamanca.

Cicha, I.; Rögl, F.; Rupp, C.; Ctyroka, J. 1998. OligoceneMiocene foraminifera of the Central Paratethys. Abhandlungen der Senckenbergischen Naturfosschenden Gessellschaft 549: 1-325. Frankfurt am Main.

Cione, A.L.; Azpelicueta, M.; Bond, M.; Carlini, A.; Casciotta, J.; Cozzuol, M.A.; De la Fuente, M.; Gasparini, Z.; Goin, F.; Noriega, J.; Scillato-Yané, G.J.; Soibelzon, L.; Tonni, E.; Verzi, D.; Vucetich, M.G. 2000. Miocene vertebrates from Entre Ríos province, eastern Argentina. In El Neógeno de Argentina (Aceñolaza, F.G.; Herbst, R.; editores), Serie Correlación Geológica 14: 191-237.

Cione, A.L.; Tonni, E. 2005. Bioestratigrafía basada en ma- míferos del Cenozoico superior de la región pampeana. In Geología y Recursos Minerales de la Provincia de Buenos Aires (De Barrio, R.E.; Etcheverry, R.O.; Caballé, M.F.; Llambías, E.; editores), Congreso Geológico Argentino, No. 16, Relatorio 11: 183-200. La Plata.

Closs, D.; Madeira, M. 1968. Cenozoic foraminifera from the Chuy drill hole, northern Uruguay. Ameghiniana 5: 229-236.

Cole, W.S. 1931. The Pliocene and Pleistocene Foraminifera of Florida. Florida Geological Survey Bulletin 6: 1-79.

Concheyro, A.; Náñez, C. 1994. Microfossils and biostratigraphy of the Jagüel and Roca Formations (Maestrichtian-Danian), province of Neuquén. Ameghiniana 31 (4): p. 397.

Criado Roque, P. 1950. Consideraciones sobre el Terciario del Sur de la Provincia de Mendoza. Asociación Geológica Argentina, Revista 5 (4): 233-255.

Cuitiño, J.I.; Scasso, R.A.; Santos, R.V; Mancini, L.H. 2015. $\mathrm{Sr}$ ages for the Chenque Formation in the Comodoro Rivadavia region (Golfo San Jorge Basin, Argentina): Stratigraphic implications. Latin American Journal of Sedimentology and Basin Analysis 22 (1): 3-12.

Cushman, J.A. 1936. Some new species of Elphidium and related genera. Contributions from the Cushman Laboratory for Foraminiferal Research 12: 78-79.

Cushman, J.A.; Ponton, G.M. 1932. The Foraminifera of the Upper, Middle, and part of the Lower Miocene of Florida. Florida State Geological Survey 9: 1-147.

Cushman, J.A.; Brönnimann, P. 1948. Some new genera and species of foraminifera from brackish water of Trinidad. Contributions from the Cushman Laboratory for Foraminiferal Research 24: 15-21.

Del Río, C.J. 1990. Composición, origen y significado paleoclimático de la malacofauna "Entrerriense" (Mioceno medio) de la Argentina. Academia Nacional de Ciencias Exactas, Físicas y Naturales, Anales 42: 207-226.

Del Río, C.J. 2000. Malacofaunas de las Formaciones Paraná y Puerto Madryn (Mioceno marino, Argentina): su origen, composición y significado bioestratigráfico. In El Neógeno de Argentina (Aceñolaza, F.G.; Herbst, R.; editores). Serie Correlación Geológica 14: 77-101.

Del Río, C.J.; Martínez, S.A. 1998. El Mioceno marino en la Argentina y en el Uruguay. In Moluscos marinos Miocenos de la Argentina y del Uruguay (Del Río, C.J., editor). Monografía de la Academia Nacional de Ciencias Exactas Físicas y Naturales 15 (1): 6-5.

Del Río, C.J.; Griffin, M.; McArthur, J.M.; Martínez, S.; Thirlwall, M.F. 2013. Evidence for early Pliocene and late Miocene transgressions in southern Patagonia 
(Argentina): ${ }^{87} \mathrm{Sr} /{ }^{86} \mathrm{Sr}$ ages of the pectinid "Chlamys" actinodes (Sowerby). Journal of South American Earth Sciences 47: 220-229.

d'Orbigny, A. 1846. Foraminifères fossiles du bassin tertiaire de Vienne (Autriche) (Die fossilen Foraminiferen des tertiären Beckens von Wien). Gide et Comp: 312 p. Paris.

Egger, J.G. 1857. Die Foraminiferen der Miocän-Schichten bei Ortenburg in Nieder-Bayern. Neues Jahrbuch für Mineralogie, Geognosie, Geologie und PetrefaktenKubde: 266-384.

Etcheverría, M.; Folguera, A.; Dal Molín, C.; Dalponte, M.; Ferro, G. 2006. Hoja 4163-II/IV y I/III, Viedma y General Conesa. Escala 1:250.000. Servicio Geológico Minero Argentino, Instituto de Geología y Recursos Minerales, Boletín 366: 1-67.

Feruglio, E. 1949. Descripción Geológica de la Patagonia. Tomo 2. Dirección General de Yacimientos Petrolíferos Fiscales. Coni: 349 p. Buenos Aires.

Fichtel, L.; von Moll, J.P.C. 1798. Testacea microscopica aliaque minuta ex generibus Argonauta et Nautilus ad naturam delineata et descripta. Camesinaischen Buchhandlung: 123 p. Viena. doi: 10.5962/bhl.title.10295.

Flynn, J.J.; Swisher, C.C. 1995. Cenozoic South American Land Mammal Ages: correlation to global geochronologies. Society of Economic Paleontologists and Mineralogists (SEPM), Special Publication 54: 317-333.

Folguera, A.; Zárate, M. 2009. La sedimentación neógena continental en el sector extrandino de Argentina central. Asociación Geológica Argentina, Revista 64 (4): 692-712.

Folguera, A.; Zárate, M.; Tedesco, A.; Dávila, F.; Ramos, V.A. 2015. Evolution of the Neogene Andean foreland basins of the Southern Pampas and Northern Patagonia $\left(34^{\circ}-41^{\circ} \mathrm{S}\right)$, Argentina. Journal of South American Earth Sciences 64: 452-466.

Frenguelli, J. 1929. Apuntes de geología patagónica. Descripción de algunos perfiles de la zona petrolífera de Comodoro Rivadavia. Boletín de Informaciones Petroleras 59-60: 576-606.

Gavriloff, I.J.C. 2013. Marine foraminifera from continental water bodies in Argentina: Dispersion hypothesis since Miocene to Recent. In Simposio del MiocenoPleistoceno del Centro y Norte de Argentina, No. 2, Libro de Resúmenes. Ameghiniana 50 (6) Suplemento, Resúmenes: p. R12.

González, M.; Musacchio, E.; García, A.; Pascual, R.; Corte, A. 1981. Las líneas de costa pleistocenas de la salina del Bebedero (San Luis, Argentina). Implicancias paleoambientales de sus microfósiles. In Congreso Geológico Argentino, No. 8, Actas 3: 617-628. San Luis.

Groeber, P. 1949. Observaciones geológicas a lo largo del meridiano $70^{\circ}$. Adiciones y correcciones. Sociedad Geológica Argentina, Revista 4 (1): 37-39.

Groeber, P. 1956. Anotaciones sobre Cretácico, Supracretácico, Paleoceno, Eoceno y Cuartario. Asociación Geológica Argentina, Revista 10 (4): 234-262.

Groeber, P. 1959. Supracretácico. In Geografía de la República Argentina, Segunda parte. Sociedad Argentina de Estudios Geográficos (GAEA): 1-165.

Gross, M.; Harzhauser, M.; Mandic, O.; Piller, W.E.; Rögl, F. 2007. A stratigraphic Enigma: The age of the Neogene deposits of Graz (Styrian Basin, Austria). Joannea Geologie und Paläontologie 9: 195-220.

Guler, M.V.; Guerstein, G.R.; Malumián, N. 2002. Bioestratigrafía de la Formación Barranca Final, Neógeno de la cuenca del Colorado, Argentina. Ameghiniana 39 (1): 103-110.

Hansen, H.J.; Likke-Andersen, A-L. 1976. Wall structure and classification of fossil and recent elphidiid and nonioniid Foraminifera. Fossils and Strata 10: 1-37.

Harzhauser, M.; Piller, W.E. 2004. Integrated stratigraphy of the Sarmatian (Upper Middle Miocene) in the western Central Paratethys. Stratigraphy 1 (1): 65-86.

Haynes, J. 1956. Certain smaller British Paleocene foraminifera. Part I. Nonionidae, Chilostomellidae, Epistominidae, Discorbidae, Amphisteginidae, Globigerinidae, Globorotaliidae, and Gümbelinidae. Contributions from the Cushman Foundation for Foraminiferal Research 7 (3): 79-101.

Hayward, B.W.; Hollis, C.J.; Grenfell, H.R. 1997. Recent Elphidiidae (Foraminiferida) of the South-West Pacific and fossil Elphidiidae of New Zealand. Institute of Geological and Nuclear Sciences, Monograph 16: 166 p.

Herbst, R.; Zabert, L.L. 1979. Nota sobre la microfauna de la Formación Camacho (Mioceno Superior) del Uruguay occidental. FACENA, Revista de la Facultad de Ciencias Exactas y Naturales y Agrimensura 3: 5-17.

Herbst, R.; Zabert, L.L. 1987. Microfauna de la Formación Paraná (Mioceno superior) de la cuenca Chaco-Paranense (Argentina). FACENA 7: 165-206.

Hernández, R.M.; Jordan, T.E.; Dalenz Farjat, A.; Echavarría, L.; Idleman, B.D.; Reynolds, J.H. 2005. Age, distribution, tectonics, and eustatic controls of the Paranense and Caribbean marine transgressions in southern Bolivia and Argentina. Journal of South American Earth Sciences 19: 495-512.

Herrero Ducloux, A.; Yrigoyen, M. R. 1952. Observaciones geológicas en la zona del Cerro Papal, provincia de 
Mendoza. Asociación Geológica Argentina, Revista 7 (2): 81-105.

Hilgen, F.J.; Lourens, L.J.; Van Dam, J.A., with contributions by Beu, A.G.; Boyes, A.F.; Cooper, R.A.; Krijgsman, W.; Ogg, J.G.; Piller, W.E.; Wilson, D.S. 2012. The Neogene Period. In The Geological Time Scale 2012, volume 1 (Gradstein, F.M.; Ogg, J.G.; Schmitz, M.; Ogg, G.; editors), Elsevier: 923-978. China.

Hottinger, L.; Reiss, Z.; Langer, M. 2001. Spiral canals of some Elphidiidae. Micropaleontology 47: 5-34.

Hugo, C.A.; Leanza, H.A. 2001. Hoja Geológica 3966III, Villa Regina, Provincia de Río Negro. Instituto de Geología y Recursos Minerales, Servicio Geológico Minero Argentino, Boletín 309: 1-53.

Jenkins, D.G. 1960. Planktonic foraminifers from the Lakes Entrance oil shaft, Victoria, Australia. Micropaleontology 6 (4): 345-371.

Jorissen, F.J. 1987. The distribution of benthic foraminifera in the Adriatic Sea. Marine Micropaleontology 12:21-48.

Jorissen, F.J. 1988. Benthic foraminifera from Adriatic Sea: principles of phenotypic variation. Utrecht Micropaleontological Bulletins 37: 1-174.

Kanmacher, F. 1798. Adam's Essays on the Microscope; the Second Edition, with Considerable Additions and Improvements. Dillon and Keating. London.

Kramarz,A.G.; Forasiepi, A.M.; Bond, M. 2011. Vertebrados cenozoicos. In Geología y Recursos Naturales de la Provincia del Neuquén (Leanza, H.; Arregui, C.; Carbone, O.; Danieli, J.C.; Vallés, J.M.; editores), Congreso Geológico Argentino, No. 18, Relatorio: 557-572. Neuquén.

Lafrenz, H.R. 1963. Foraminiferen aus dem marinen Riss-Würm-Interglazial (Eem) in Schleswig-Holstein. Meyniana 13: 10-46.

Loeblich, A.R.; Tappan, H. 1964. Part C: Protista 2, Sarcodina chiefly "Thecamoebians" and Foraminiferida. In Treatise of Invertebrate Paleontology (Moore, R.C.; editor), University of Kansas Press and the Geological Society of America: 900 p. Lawrence.

Loeblich, A.R.; Tappan, H. 1987. Foraminiferal genera and their classification. Van Nostrand Reinhold, vol. 1: 1-970, vol. 2: 1-212 + 847 pl. New York.

Lourens, L.; Hilgen, F.; Shackleton, N.J.; Laskar, J.; Wilson, D. 2004. The Neogene Period. In A Geological Time Scale 2004 (Gradstein, F.; Ogg, J.; Smith, A.; editors). Cambridge University Press: 409-440. Cambridge.

Madeira Falcetta, M.; Thiesen, Z.V. 1988. Foraminíferos da perfuração 2-GAst-1A-RS. Bacia de Pelotas. Pesquisas em Geociências 21: 49-59.
Malumián, N. 1970. Bioestratigrafía del Terciario marino del subsuelo de la provincia de Buenos Aires (Argentina). Ameghiniana 7: 173-204.

Malumián, N. 1972. Foraminíferos del Oligoceno y Mioceno del subsuelo de la provincia de Buenos Aires. Ameghiniana 9: 97-137.

Malumián, N. 1978. Esbozo paleoecológico de las asociaciones foraminiferológicas terciarias de la Argentina. Ameghiniana 15 (1-2): 161-171.

Malumián, N. 1999. La sedimentación en la Patagonia extraandina. In Geología Argentina (Caminos, R.; editor). Instituto de Geología y Recursos Minerales, Servicio Geológico Minero Argentino, Anales 29 (18): 557-578.

Malumián, N.; Masiuk, V. 1973. Asociaciones foraminiferológicas fósiles de la República Argentina. In Congreso Geológico Argentino, No. 5, Actas 3: 433-453. Córdoba.

Malumián, N.; Náñez, C. 1984. A- Foraminíferos. In Geología y Recursos Naturales de la Provincia de Río Negro (Ramos, V.; editor), Congreso Geológico Argentino, No. 9, Relatorio II-7: 486-501. San Carlos de Bariloche.

Malumián, N.; Caramés, A. 1995. El Daniano marino de Patagonia (Argentina): paleobiogeografía de los foraminíferos bentónicos. In Paleógeno de América del Sur (Náñez, C.; editor). Asociación Paleontológica Argentina, Publicación Especial 3: 83-105.

Malumián, N.; Náñez, C. 1996. Microfósiles y nanofósiles calcáreos de la plataforma continental. In Geología y Recursos Naturales de la Plataforma Continental (Ramos, V.A.; Turic, M.; editores), Congreso Geológico Argentino, No. 13 y Congreso de Exploración de Hidrocarburos, No. 3, Relatorio, 5: 73-93. Buenos Aires.

Malumián, N.; Náñez, C. 2011. The Late CretaceousCenozoic transgressions in Patagonia and the Fuegian Andes: foraminifera, paleoecology, and paleogeography. Biological Journal of the Linnean Society 103: 269-288.

Malumián, N.; Suriano, J. M.; Cobos, J.C. 1998. La Formación Barranca Final en su localidad tipo. Mioceno, cuenca del Colorado. In Congreso Latinoamericano de Geología, No. 10 y Congreso Nacional de Geología Económica, No. 6, Actas 1: 125-130. Buenos Aires.

Marengo, H.G. 2000. Rasgos micropaleontológicos de los depósitos de la transgresión Entrerriense-Paranense en la cuenca Chaco-Paranense y Noroeste Argentino. In El Neógeno de Argentina (Aceñolaza, F.; Herbst, R.; editores). Serie Correlación Geológica 14: 29-45. 
Marengo, H.G. 2006. Micropaleontología y estratigrafía del Mioceno marino de la Argentina: Las transgresiones de Laguna Paiva y del Entrerriense-Paranense. Tesis doctoral (Inédita), Facultad de Ciencias Exactas, Físicas y Naturales, Universidad de Buenos Aires: $246 \mathrm{p}$.

Marengo, H.G. 2015. Neogene micropaleontology and Stratigraphy of Argentina. The Chaco-Paranense Basin and the Península de Valdés. SpringerBriefs in Earth System Sciences 14: 218 p.

Marengo, H.G.; Concheyro, A. 2001. Foraminíferos y nanofósiles calcáreos del subsuelo de la ciudad de Buenos Aires y alrededores. In Congreso Latinoamericano de Geología No. 11 y Congreso Uruguayo de Geología, No. 3, Actas en CD ROM. Montevideo.

Marengo, H.G.; Echevarría, A.; Concheyro, A. 2005. Microfósiles marinos miocenos del subsuelo de la ciudad de Buenos Aires y alrededores. In Congreso Geológico Argentino, No. 16, Actas: 317-324. La Plata.

Marinelli, R.V.; Franzin, H.J. 1996. Cuencas de Rawson y Península de Valdés. In Geología y Recursos Naturales de la Plataforma Continental (Ramos, V.A.; Turic, M.; editores), Congreso Geológico Argentino, No. 13 y Congreso de Exploración de Hidrocarburos, No. 3, Relatorio, 9: 159-169. Buenos Aires.

Marks, P. 1951. A revision of the smaller foraminifera from the Miocene of the Vienna Basin. Contributions from the Cushman Foundation for Foraminiferal Research 2: 33-73.

Martínez, S.; Del Río, J. 2005. Las ingresiones marinas del Neógeno en el sur de Entre Ríos (Argentina) y litoral oeste de Uruguay y su contenido malacológico. In Temas de la Biodiversidad del Litoral fluvial argentino II (Aceñolaza, F.G.; coordinador). Miscelánea, Instituto Superior de Correlación Geológica 14: 13-26.

Martini, E. 1971. Standard Tertiary and Quaternary calcareous nannoplankton zonation. In Second Planktonic Conference (1970), (Farinacci, A.; editor) Proceedings 2: 739-785. Roma.

Masiuk, V. 1967. Estratigrafía del Rocanense del Puesto Álvarez, curso inferior del Río Chico, Provincia del Chubut. Revista del Museo La Plata (nueva serie) Paleontología 5 (34): 197-258.

Masiuk, V.; Becker, D.; García Espiasse, A. 1976. Micropaleontología y sedimentología del Pozo YPF. Ch.Pv.es-1 (Península Valdés), Provincia del Chubut, República Argentina. Importancia y correlaciones. Arpel 14: 1-28.

Méndez, I.A. 1966. Foraminíferos, edad y correlación estratigráfica del Salamanquense de Punta Peligro ( $45^{\circ}$
30' S; 67¹1' W), provincia del Chubut. Asociación Geológica Argentina, Revista 21 (2): 127-157.

Montalvo, C.I.; Casadío, S. 1988. Presencia del género Palaeoctodon (Rodentia, Octodontidae) en el Huayqueriense (Mioceno tardío) de la Provincia de La Pampa. Ameghiniana 25: 111-114.

Montfort, P. Denys de 1808. Conchyliologie Systématique et Classification Méthodique des Coquilles 1, F. Schoell: 409 p. Paris.

Murray, J.W. ; Wright, C.A. 1974. Paleogene Foraminiferida and Palaeoecology, Hampshire and Paris Basins and the English Channel. Special Papers in Palaeontology 14: $1-129$.

Náñez, C. 1989. Paleoecología de los foraminíferos del Terciario medio de la región oriental de la provincia de Santa Cruz. Tesis doctoral (Inédito), Universidad de Buenos Aires: 325 p.

Náñez, C. 1998. The genus Boltovskoyella (foraminifera) from Patagonia. Journal of Micropalaeontology 17: 105-118.

Náñez, C.; Concheyro, A. 1997. Límite Cretácico-Paleogeno. In Geología y Recursos Minerales del Departamento Añelo. Provincia del Neuquén. República Argentina (Ardolino, A.; Franchi, M.; editores). Dirección Nacional del Servicio Geológico, Anales 25 y Dirección Provincial de Minería, Boletín 3: 129-149.

Náñez, C.; Malumián, N. 2008. Paleobiogeografía y paleogeografía del Maastrichtiense marino de la Patagonia, Tierra del Fuego y la Plataforma Continental Argentina, según sus foraminíferos bentónicos. Revista Española de Paleontología 23 (2): 273-300.

Náñez, C.; Parras, A.; Hansen, H.J.; Concheyro, A.; Alonso, S.; Lojen, S.; Pires, M. 2002. A southern, shallow marine, Cretaceous-Paleogene boundary: Bajada del Jagüel section, Neuquén Basin, Argentina. In Geological Association of Canada, Mineralogical Association of Canada, Joint Annual Meeting, Abstract Volume 27: 79. Saskatoon.

Palazzesi, L.; Barreda, V.D.; Cuitiño, J.I.; Guler, M.V.; Tellería, M.C.; Ventura Santos, R. 2014. Fossil pollen records indicate that Patagonian desertification was not solely a consequence of Andean uplift. Nature Communications 5: 1-8.

Papp, A.; Schmid, M.E. 1985. Die Fossilen Foraminiferen des Tertiären Beckens von Wien. Abhandlugen der Geologischen Bundesanstalt 37: 1- 311.

Parras, A.; Casadío, S.; Pires, M. 1998. Secuencias depositacionales del Grupo Malargüe y el límite Cretácico-Paleógeno en el sur de la provincia de Mendoza, Argentina. In Paleógeno de América del 
Sur y de la Península Antártica (Casadío, S.; editor). Asociación Paleontológica Argentina, Publicación Especial 5: 61-69.

Parras, A.; Malumián, N.; Camilletti, C.; De Elorriaga, E.; Visconti, G.; Fernández, M. 2000. Invertebrados marinos del Neógeno en el sureste de la provincia de La Pampa, Argentina. Ameghiniana 37 (4), Suplemento: p. 77 R.

Pascual, R.; Bondesio, P.; Vucetich, M.G.; Scillato Yané, G.J.; Bond, M.; Tonni, E.P. 1984. Vertebrados fósiles cenozoicos. In Geología y Recursos Naturales de la Provincia de Río Negro (Ramos, V.; editor), Congreso Geológico Argentino, No. 9, Relatorio: 439-461. San Carlos de Bariloche.

Patterson, R.T. 1987. Arcellaceans and foraminifera from Pleistocene lake Tecopa, California. Journal of Foraminiferal Research 17 (4): 333-343.

Pérez, L.M. 2013. Nuevo aporte al conocimiento de la edad de la Formación Paraná, Mioceno de la provincia de Entre Ríos, Argentina. In Neógeno de la Mesopotamia Argentina (Brandoni, D.; Noriega, J.L.; editores), Asociación Paleontológica Argentina, Publicación Especial 14: 7-12.

Pérez, D.J.; Ottone, G.; Ramos, V.A. 1996. La ingresión marina miocena en la Provincia de San Juan: sus implicancias paleogeográficas. In Congreso Geológico Argentino, No. 13, Actas 1: 385-398. Buenos Aires.

Pérez-Panera, J.P.; Calvo Marcilese, L.; Angelozzi, G. 2015. Microfósiles calcáreos del límite CretácicoPaleógeno en el pozo Las Chilcas x-1, cuenca del Salado, Argentina. In Reunión de Comunicaciones de la Asociación Paleontológica Argentina, Resúmenes: 72-73. Mar del Plata.

Pisetta, J. 1968. Descripción de una fáunula de Foraminíferos de la Provincia de Entre Ríos. Trabajo final de Licenciatura (Inédito). Facultad de Ciencias Exactas Físicas y Naturales, Universidad de Buenos Aires: 64 p.

Poignant, A.; Mathieu, R.; Levy, A.; Cahuzac, B. 2000. Haynesina germanica (Ehrenberg), Elphidium excavatum (Terquem) 1.s. et Porosononion granosum (d'Orbigny), espèces margino-littorales de foraminiféres d'Aquitaine centrale (SO France) au Miocène Moyen (Langhien). Le problème d'Elphidium lidoense Cushman. Revue de Micropaléontologie 43: 393-405.

Ramos, V.A. 1981. Descripción geológica de la Hoja 33c, Los Chihuidos norte, provincia del Neuquén. Servicio Geológico Nacional, Boletín 182: 1-103.

Ramos, V.A.; Alonso, R.N. 1995. El mar paranense en la provincia de Jujuy. Revista del Instituto de Geología y Minería 10: 73-80.
Rodríguez, M.F.; Leanza, H.A.; Salvarredy Aranguren, M. 2007. Hoja Geológica 3969-II, Neuquén, provincias del Neuquén, Río Negro y La Pampa. Programa Nacional de Cartas Geológicas de la República Argentina a escala 1:250.000. Instituto de Geología y Recursos Minerales. Servicio Geológico Minero Argentino, Boletín 370: 1-172.

Rossi de García, E. 1966. Contribución al conocimiento de los ostrácodos de la Argentina y Formación Entre Ríos, de Victoria, provincia de Entre Ríos. Asociación Geológica Argentina, Revista 3: 194-208.

Ruskin, B.G.; Dávila, F. M.; Hoke, G.D.; Jordan, T. E.; Astini, R.A.; Alonso, R. 2011. Stable isotope composition of middle Miocene carbonates of the Frontal Cordillera and Sierras Pampeanas: Did the Paranaense seaway flood western and central Argentina? Palaeogeography, Palaeoclimatology, Palaeoecology 308: 293-303.

Scasso, R.A.; MacArthur, J.M.; Del Río, C.J.; Martínez, S.; Thirlwall, M.F. 2001. ${ }^{87} \mathrm{Sr} /{ }^{86} \mathrm{Sr}$ Late Miocene age of fossil mollusks in the "Entrerriense" of the Valdés Peninsula (Chubut, Argentina). Journal of South American Earth Sciences 14: 319-329.

Simeoni, G. 2009. Nannofósiles del Serravalliano (Mioceno) en Patagonia, Argentina [Serravallian (Miocene) nannofossils in Patagonia, Argentina]. Carnets de Géologie /Notebooks on Geology, Letter 2009/01 (CGm2009 L01): 1-10.

Sprechmann, P. 1978. The Paleoecology and paleogeography of the Uruguayan coastal area during the Neogene and Quaternary. Zitteliana 4: 3-72.

Sprechmann, P.; Chemale, F. Jr.; Gaucher, C. 2008. Presencia del Burdigaliense en las secuencias basales en la Perforación IGU Chuy $\mathrm{N}^{\circ} 364$ del Uruguay datadas con ${ }^{87} \mathrm{Sr} /{ }^{86} \mathrm{Sr}$ en tecas de foraminíferos Cibicides. In Regional Committee on Atlantic Neogene Stratigraphy Congress, No. 4, Abstracts: 52. Buenos Aires.

Sprechmann, P.; Gaucher, C.; Frei, R. 2010. Identificación del Burdigaliense (Mioceno temprano) en ostreidos procedentes de afloramientos de la Formación Camacho de Uruguay datados con ${ }^{87} \mathrm{Sr} /{ }^{86} \mathrm{Sr}$. In Congreso Argentino de Paleontología y Bioestratigrafía, No. 10, y Congreso Latinoamericano de Paleontología, No. 7: 106. La Plata.

Tapia, A. 1929. Algunas observaciones sobre las relaciones estratigráficas de los estratos con dinosaurios y los depósitos eocenos con mamíferos de la región del Golfo de San Jorge. Anales de la Sociedad Argentina de Estudios Geográficos, GAEA 3 (2): 489-504.

Ten Dam, A. 1944. Die stratigraphische Gliederung des niederländischen Paläozäns und Eozäns nach Foraminiferen (mit Ausnahme von Süd-Limburg). 
Mededeelingen van de Geologische Stichting, Ser. C 5 (3): 1-142.

Uliana, M. 1979.Geología de la región comprendida entre los ríos Colorado y Negro, Provincias de Neuquén y Río Negro. Tesis doctoral (Inédito), Universidad Nacional de La Plata: 117 p.

Uliana, M.A.; Camacho, H.H. 1975. Estratigrafía y paleontología de la Formación Vaca Mahuida (Provincia de Río Negro). In Congreso Argentino de Paleontología y Bioestratigrafía, No. 1, Actas 2: 357-376. Tucumán.

Uliana, M.A.; Dellapé, D.A. 1981. Estratigrafía y evolución paleoambiental de la sucesión eoterciaria del Engolfamiento Neuquino (Patagonia septentrional). In Congreso Geológico Argentino, No. 8, Actas 3: 673-711. San Luis.

Verzi, D.H.; Montalvo, C.I.; Deschamps, C.M. 2008. Biostratigraphy and biochronology of the Late Miocene of central Argentina: evidence from rodents and taphonomy. Geobios 41: 145-155.

Visconti, G.; De Elorriaga, E.E.; Parras, A. 2003. Sedimentitas marinas de la Formación Barranca Final (Mioceno medio-superior de la cuenca del Colorado), aflorantes en el sureste de la provincia de La Pampa, Argentina. Asociación Geológica Argentina, Revista 58: 187-193.

Voloshinova, N.A. 1958. About a new systematics of the Nonionidae. Microfauna of the USSR, Proceedings of the Oil Research Geological Institute (VNIGRI) 115: 117-223.

Voltski, I.; Korsun, S.; Pillet, L.; Pawlowski, J. 2015. Protelphidium niveum (Lafrenz, 1963), and the taxonomy of "lower" elphidiids. Journal of Foraminiferal Research 45 (3): 250-263.

Wichmann, R. 1922. Algunas nuevas observaciones geológicas en la parte oriental del territorio del Neuquén. Physis 5: 301-303.

Wichmann, R. 1924. Nuevas observaciones geológicas en la parte oriental del Neuquén y en el territorio de Río Negro. Ministerio de Agricultura de la Nación, Dirección General de Minas, Geología e Hidrología (Sección: Geología), Publicación 2: 3-22.
Windhausen, A. 1912. El yacimiento de "Rafaelita" de Auca Mahuida (Territorio del Neuquén). Informe preliminar. Informes preliminares de la Dirección General de Minería, Geología e Hidrogeología 1: 3-41.

Windhausen, A. 1914. Contribución al conocimiento geológico de los Territorios del Río Negro y Neuquén. Anales del Ministerio de Agricultura, Sección Geología y Minería 10 (1): 1-60.

Windhausen, A. 1931. Geología Argentina. Segunda Parte. Jacobo Peuser, Ltda.: 645 p. Buenos Aires.

Young, J.R. 1998. Neogene. In Calcareous Nannofossil Biostratigraphy (Bown, P.R.; editor). Chapman \& Hall: 225-265. Londres.

Yrigoyen, M.R. 1993. Los depósitos sinorogénicos terciarios. In Geología y Recursos Naturales de Mendoza (Ramos, V.A.; editor). Congreso Geológico Argentino, No. 12, y Congreso de Exploración de Hidrocarburos, No. 11, Relatorio I-11: 123-148. Mendoza.

Yrigoyen, M.R. 1999. Los depósitos cretácicos y terciarios de las cuencas del Salado y del Colorado. In Geología Argentina (Caminos, R.; editor). Instituto de Geología y Recursos Minerales, Servicio Geológico Minero Argentino, Anales 29 (21): 645-649.

Zabert, L.L.; Herbst, R. 1977. Revisión de la microfauna miocena de la Formación Paraná (entre Victoria y Villa Urquiza-Provincia de Entre Ríos-Argentina), con algunas consideraciones estratigráficas. FACENA, Revista de la Facultad de Ciencias Exactas y Naturales y Agrimensura 1: 131-168.

Zabert, L.L.; Barbano, J. 1982-1984. Microfósiles miocénicos (Formación Paraná) de Córdoba, Santiago del Estero y nuevas descripciones de Entre Ríos. FACENA, Revista de la Facultad de Ciencias Exactas y Naturales y Agrimensura 5: 135-150.

Zavala, C.; Freije, H. 2000. Estratigrafía secuencial del Terciario superior marino de Patagonia. Un equivalente de la "crisis del Messiniano"? Geotemas 1 (2): 217-221.

Zinsmeister, W.J.; Marshall, L.G.; Drake, R.E.; Curtis, G.H. 1981. First radioisotope (Potassium-Argon) age of marine Neogene Rionegro beds in northeastern Patagonia, Argentina. Science 212: 440.

Manuscript received: December 29, 2017; revised/accepted: February 27, 2018; available online: October 31, 2018. 